\title{
Performance Evaluation of Alumina-graphene Hybrid Nano-cutting Fluid in Hard Turning of AISI 304 Steel
}

\begin{abstract}
Nanofluid (NF) is a colloidal mixture of metallic or non-metallic particles of nanometre-size in a base fluid. In the present investigation, a hybrid nano-cutting fluid with better thermal and tribological properties has been developed by mixing alumina based nanofluid with graphene nanoplatelets $(\mathrm{GnP})$ in the volumetric concentrations of $0.25,0.75$ and 1.25 vol. \%. The prepared hybrid and alumina mixed nanofluids are characterized for their thermal conductivity, viscosity, specific heat and density in various nanoparticle concentrations at different temperatures. Furthermore, pin on disc testing and contact angle measurement of all nanofluid samples are performed to understand their tribological behaviour and wettability, respectively. Later the performance of the prepared cutting fluid was evaluated during turning of AISI 304 steel under minimum quantity lubrication (MQL) technique. The results have also been compared with the results obtained with that of alumina nanofluid. The results clearly establish that the performance of hybrid nanofluid, in terms of cutting force, feed force, thrust force and surface roughness, is significantly better as compared to alumina nanoparticle mixed cutting fluid.
\end{abstract}

Keywords: Hybrid; nanofluid; MQL; Graphene; Roughness; Force; Turning

\section{Introduction}

In the manufacturing industry, during dry machining of steel, due to high degree of heat generation at the machining zone, cutting velocity of the tool gets restricted. Moreover, the heat affects hardness and sharpness of the cutting tools and result in their premature breakage. Therefore, a suitable cutting fluid becomes necessary in order to overcome these difficulties in high speed machining. Cutting fluid plays a vital role by cooling and lubricating the cutting tool work piece interface and washing away the chips from machining zone. This conventional way of cooling, however, serves the purpose up to an extent. Excessive use of the conventional cutting fluids pollutes the environment and may even be hazardous for human beings.

To restrict excessive use of conventional cutting fluids, MQL/NDM (near dry machining) has emerged as a promising technique. In this technique, a small quantity of any cutting fluid has to be sprayed into the cutting zone at high pressure so that it can penetrate the machining zone properly. Cetin et al. (2011) found that the MQL technique is capable of spraying cutting fluid into the cutting zone optimally. Hadad and sadeghi (2013) noticed that the best surface quality could be achieved over entire range of depth of cut by using the MQL technique in turning of 4140 alloy steel. A few researchers like Sharma et al. (2016) and Sarikya and Gullu (2015) concluded that the use of the MQL technique improves the surface finish, tool life and reduces impact of the cutting forces. In their opinion, it can be a viable alternative to wet machining because the MQL technique can minimize both, the manufacturing cost and the environmental hazards. 
Conventional fluids may possess good lubrication properties but poor thermal properties in them restrict their use as cutting fluid for industrial purpose. By mixing milli or micro-sized solid particles, thermal conductivity (heat extraction capability) of conventional fluids may be increased. However, use of micro-sized particles may create serious problems of clogging and pressure drop in pipelines. They also have poor stability of suspension. To overcome these problems, nanometresized particles have replaced micro particles, leading to the synthesis of a new generation fluids, which are called 'nanofluids'. The use of these nanofluids has shown a noticeably improved performance in different machining processes.

Tiwari et al. (2012) reported a significant improvement in thermal conductivity of conventional fluid (water) by the inclusion of different nanoparticles and noticed a further enhancement with a rise of nanoparticle volumetric concentration in the base fluid. Few researchers like Yang (2006) and Choi et al. (2001) noticed a massive increment of approx. 200\% and 150\% respectively in thermal conductivity when multi-walled carbon nanotube (MWCNT) was added to the base fluid. Moreover, Sharma et al. (2015a) reviewed various published research works on nano-cutting fluid and found that mixing of nanoparticles into cutting fluid enhances its thermal conductivity, which in turn, improves the tool life and reduces the cutting force, surface roughness and cutting temperature.

Besides thermal conductivity of cutting fluid, the friction between cutting tool and work piece interface plays a critical role in heat generation at machining zone. It increases the tool tip temperature, and, in turn, may also decrease hardness and sharpness of the tool cutting edge. As a result, the surface finish gets affected and the tool wear is aggravated. Sharma et al. (2015b) investigated the performance of the multi walled carbon nanotube (MWCNT) enriched cutting fluid in turning of AISI D2 steel and noticed an appreciable reduction in tool temperature and surface roughness. It has been found that addition of graphite nanoparticles into the base fluid enhances its tribological property due to reduced coefficient of friction (Lee et al., 2009). Due to their low friction behaviour, $\mathrm{MoS}_{2}$ and graphite solid lubricants reduce surface roughness and cutting force during machining (Reddy and Rao, 2006). They also ensure an improved surface quality and a reduction in tool wear, cutting force and chip thickness compared to dry and conventional wet machining (Khandekar et al., 2012). Park et al. (2011) investigated the effect of graphene nanoplatelets enriched vegetable oil in milling operation. They observed an improved wettability and reduced friction at the machining zone which in turn reduced the tool wear and yielded better machining performance. Sayuti et al. (2014) examined the novel use of $\mathrm{SiO}_{2}$ nanoparticle enriched cutting fluid in hard turning and observed less cutting fluid consumption with better surface quality and tool wear. Albert et al. (2009) used graphene enriched mineral oil in grinding and achieved a significant reduction in surface roughness, grinding forces and specific energy consumption. Moreover, Amrita et al. (2014) evaluated the performance of nano-graphite based nano cutting fluid in turning and found that MQL method reduces the surface roughness, cutting force, cutting temperature and tool wear by $30 \%, 54 \%, 25 \%$ and $71 \%$, respectively, in comparison with the conventional wet machining. 
The exhaustive literature review by Sharma et al. (2015a) reveals a lot of work being carried out in the field of conventional machining with nano-cutting fluids enriched with a single type of nanoparticles. However, to the best of author's knowledge, very few investigations have been performed with the use of hybrid nanofluids (i.e. a colloidal suspension enriched by two different types of nanoparticles). Moreover, Sarkar et al. (2015) reviewed the available literature on hybrid nanofluids and concluded that the proper hybridization might be helpful in making hybrid nanofluids very auspicious for heat transfer enhancement. Zhang et al. (2016) in their investigation on lubrication performance of $\mathrm{Al}_{2} \mathrm{O}_{3}-\mathrm{SiC}$ enriched nanofluid during $\mathrm{MQL}$ grinding of Ni-based alloy opined that the $\mathrm{Al}_{2} \mathrm{O}_{3}$-SiC enriched nanofluid yielded better surface quality compared with pure nanoparticles. Furthermore, Ahammed et al. (2016) recorded an enhancement of $88.62 \%$ in convective heat transfer coefficient and a reduction of $4.7^{\circ} \mathrm{C}$ in equipment temperature by the use of alumina-graphene hybrid nanofluid. Zhang et al. (2015) used $\mathrm{MoS}_{2}$-CNT hybrid nanofluid in grinding operation and observed that for the same mass fraction, $\mathrm{MoS}_{2}-\mathrm{CNTs}$ hybrid nanofluid achieved lower $\mathrm{G}$ ratio and surface roughness $\left(\mathrm{R}_{\mathrm{a}}=0.328 \mu \mathrm{m}\right)$ compared with pure $\mathrm{MoS}_{2}$ and CNT nanoparticles. This may be attributed to the physical collaboration of the mixed nanoparticles. Many researchers have also performed the thermos-physical characterization of hybrid nanofluids and found that hybridization of different types of nanoparticles may enhance the thermos-physical (Abbasi et al., 2013) and tribological (Kanthavel et al., 2016) properties of base nanofluid. However not much significant work could be reported in literature regarding the application of hybrid nanofluids as a cutting fluid in machining, especially in turning operation.

In present work, a hybrid nano-cutting fluid has been developed by mixing graphene nanoplatelets with alumina based nanofluid in different volumetric concentrations of $0.25,0.75$ and 1.25 vol. \%. All the nanofluid samples have been tested for their thermal conductivity and viscosity at different temperatures in different concentrations followed by the study of their wettability in terms of contact angle and tribological behaviour on pin on disc testing machine. At last, their performances as a cutting fluid has been evaluated in turning of AISI 304 steel regarding three components of machining forces (cutting, thrust, and feed force) and surface roughness by using minimum quantity lubrication (MQL) technique. The results are also compared with the performance of alumina nanoparticle mixed cutting fluid.

\section{Experimental Procedure}

Prior to the application of nanofluids in machining, the samples were tested for thermophysical properties such as thermal conductivity and viscosity followed by their tribological testing and wettability study.

\subsection{Preparation and characterization of nanofluids}

The commercially available colloidal suspension containing 25 vol.\% of $\mathrm{Al}_{2} \mathrm{O}_{3}$ nanoparticles (spherical in shape with $45 \mathrm{~nm}$ in diameter) in water, was procured from Alfa $\mathrm{Aesar}^{\circledR}$ and water based colloidal suspension containing 18 vol.\% of graphene (average thickness: $11-15 \mathrm{~nm}$, average particle size: 5 microns) was purchased from Sigma Aldrich. The surfactant CTAB was already added to the suspension by the manufacturer. The alumina-graphene (Al-GnP) hybrid nanofluid 
was prepared by mixing $\mathrm{Al}_{2} \mathrm{O}_{3}$ with graphene nanoplatelets $(\mathrm{GnP})$ in volumetric ratio of $90: 10$ in the same base fluid in three volumetric concentrations $(0.25 \%, 0.75 \%$ and $1.25 \%$ vol.). The base fluid was prepared by mixing 5 vol. $\%$ vegetable oil in deionized water. The detergent in volumetric proportion of $0.5 \%$ was used as an emulsifier to get stable emulsion (base fluid). The TEM images shown in Fig. 1 justify the size of nanoparticles present in colloidal suspension.
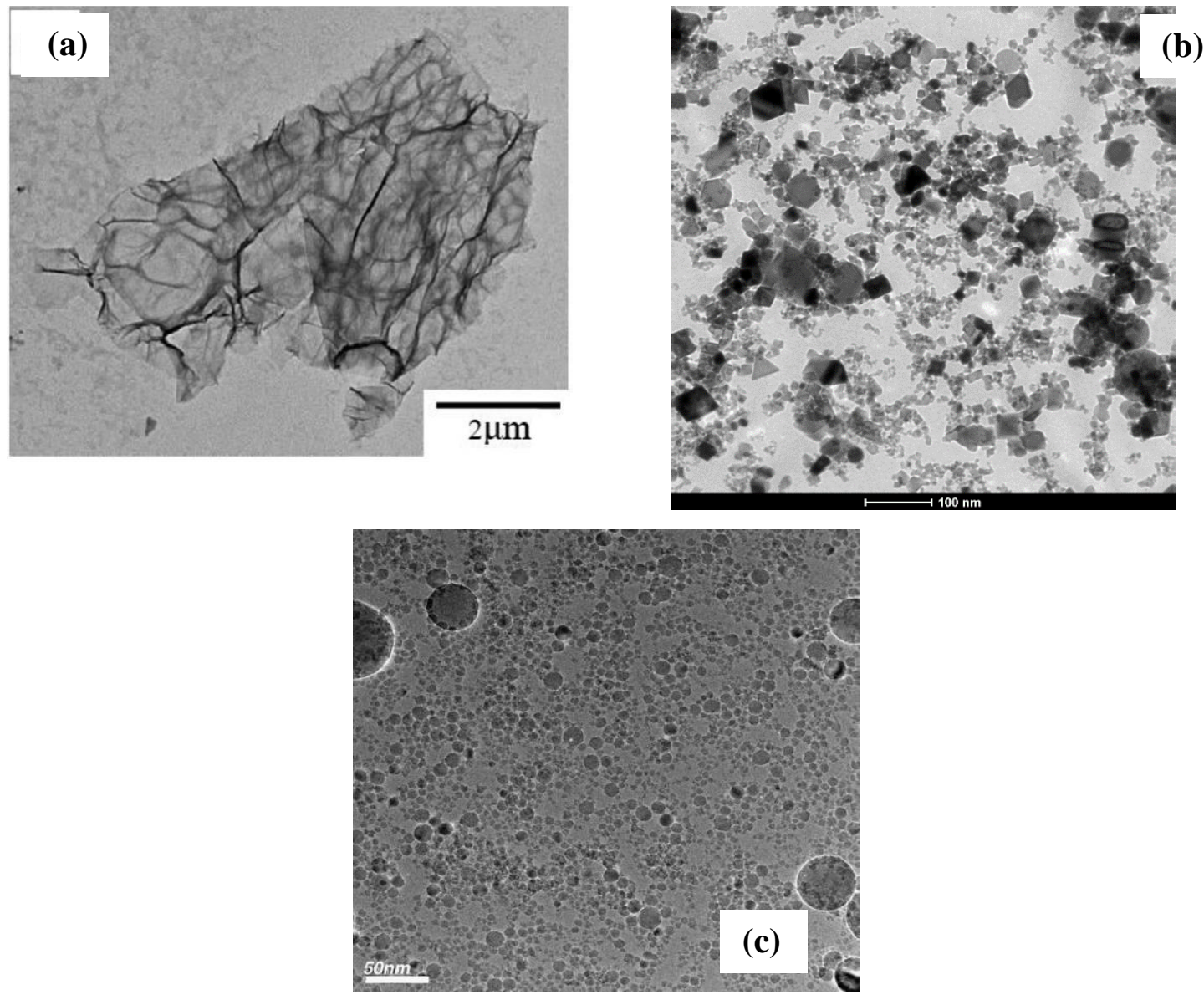

Fig.1 TEM images of (a) GnP (b) Alumina nanofluid and (c) Al-GnP hybrid nanofluid

The prepared nano fluids were kept in ultrasonicator (Toshiba, India), generating 100W ultrasonic pulses at $36 \pm 3 \mathrm{kHz}$ at a stretch for 6 hours to get a homogeneous and stable suspension. A fresh nano-cutting fluid sample was developed for each test and used immediately to avoid possible agglomeration/sedimentation. The prepared hybrid nanofluids were tested for thermo physical properties (thermal conductivity and viscosity) at five temperatures: 25, 35, 40, 45 and 50 ${ }^{\circ} \mathrm{C}$. The effect of nanoparticle concentration on its properties was also studied. A transient hot wire apparatus (Decagon Devices, Inc., USA) was used to determine nanofluids' thermal conductivity. The hot-wire measures the thermal conductivity and thermal resistivity from the rate of rise in temperature of the probe for constant rate of heating. The viscosity of various nanofluids was 
measured with the help of digital viscometer equipped with a temperature bath which sets the temperature of nanofluid at different values.

The Al-GnP hybrid nanofluid shows an improvement in thermal conductivity over base fluid while surprisingly, the hybridization of alumina with $\mathrm{GnP}$ reduced its (hybrid nanofluid) thermal conductivity compared to pure alumina nanofluid. An enhancement of $9.38 \%$ in thermal conductivity could be observed by the blending of graphene, however alumina alone has shown an improvement of 9.85\%, even better than Al-GnP hybrid nanofluids as illustrated in Fig 2.

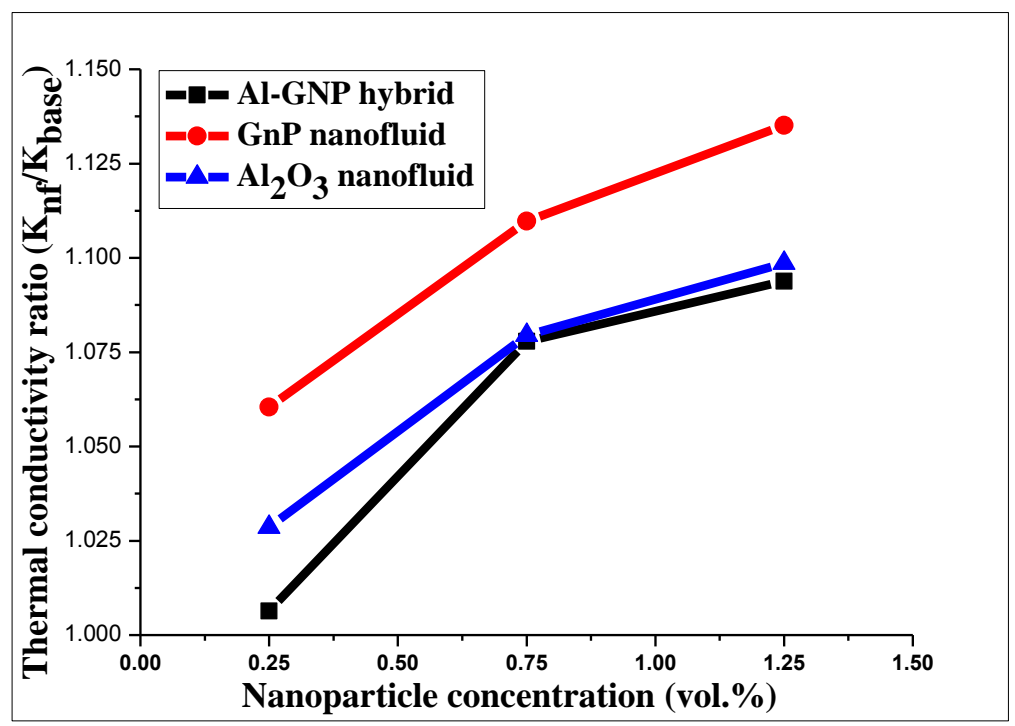

Fig. 2 Thermal conductivity ratio of nanofluids at different nanoparticle concentrations

All the hybrid nanofluids samples have shown a reduction in viscosity with increase of temperature. Fig. 3 clearly shows an increment of $17.69 \%, 25.19 \%$, and $31.53 \%$ in viscosity of Al$\mathrm{GnP}$ hybrid nanofluid for concentration of $0.25 \%, 0.75 \%$ and $1.25 \%$, respectively. Further it is found that all the nanofluids show a reduction in viscosity with rise of temperature largely following the behaviour of pure water for small particle content. 


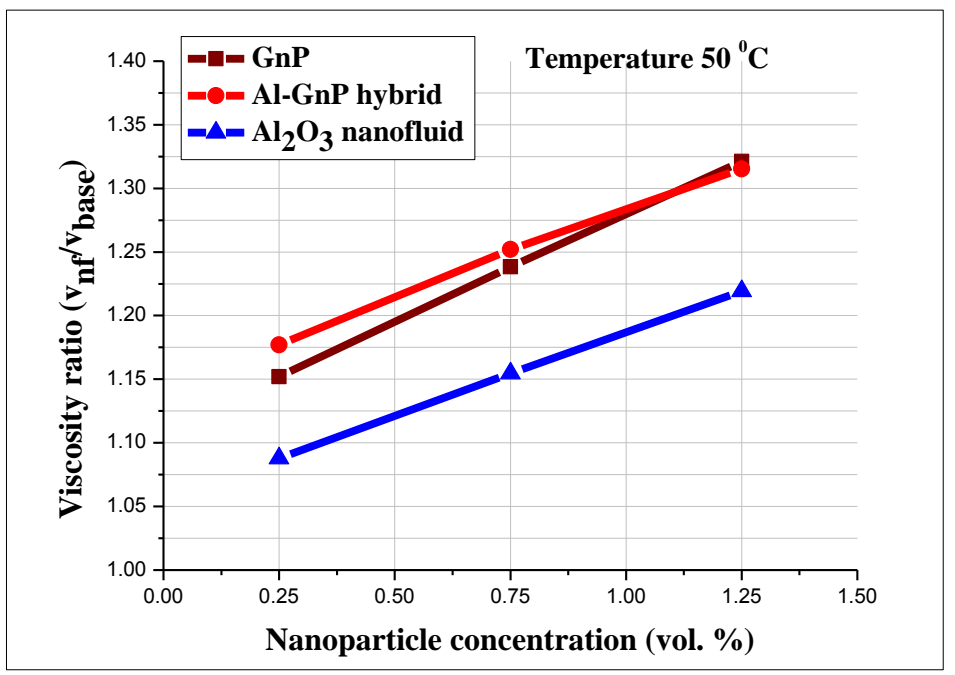

Fig. 3 Viscosity ratio of different nanofluids at different nanoparticle concentrations

This observation clearly reveals that an increase of nanoparticle concentration enhances both, the thermal conductivity and viscosity. Thermal conductivity positively affects the cooling of the tool-work piece interface while higher viscosity creates problem (pressure drop due to high viscosity) while spraying nano-cutting fluid with the MQL technique. In order to balance the benefit of higher thermal conductivity and the loss of pumping power due to high viscosity, the authors selected a volumetric range of 0.25 vol. \% to 1.25 vol. \% for further experimental investigation. Later, all the nanofluids samples were kept on ultrasonic vibrator for about two hours to get a homogeneous and stable nanofluid. As a result, during further tribological study, wettability testing and turning operation, no precipitation of nanoparticles was noticed. Furthermore, nanofluids' specific heat and density variation were measured.

\subsection{Tribology testing of nanofluids}

The determination of experimental value of coefficient of friction in turning operation is a tidious task. Therfore, to understand the tribological behaviour of nanofluids, a series of experiments were performed on a pin on disc wear and friction tester TR-20 (Ducom, India) with maximum speed and load capacity of 2000 RPM and $1000 \mathrm{~N}$, respectively. The complete experimental setup is illustrated in Fig 4. Cylindrical pin (Dia. $3 \mathrm{~mm}$, length $40 \mathrm{~mm}$ ) and disc (pitch circle dia. $155 \mathrm{~mm}$ ) made up of AISI 304 steel were used in this experiment. During the experiments, the load, linear speed and time were kept constant at $40 \mathrm{~N}, 1 \mathrm{~m} / \mathrm{s}$ and 5 min, respectively. The sliding track of pin was changed after each run to ensure the availability of fresh surface to next run and to maintain the constant sliding speed, RPM of the disc were changed 
accordingly. The steel disc was cleaned with acetone after each run to ensure smooth and clean disc surface.
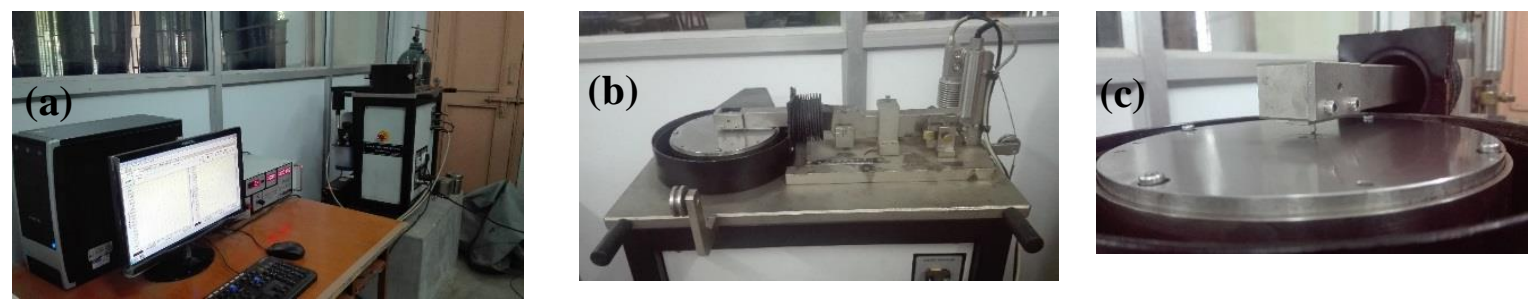

Fig 4 (a) Pin-on-disc experimental setup (b) Pin and Disc machine (c) closed view of sliding pin on rotating disc

The different samples of $\mathrm{Al}_{2} \mathrm{O}_{3}$ nanofluid, $\mathrm{Al}-\mathrm{GnP}$ hybrid nanofluid in three volumetric concentrations $(0.25,0.75$ and $1.25 \mathrm{vol} . \%)$ and base fluid (5 vol. \% oil-water emulsion) were used as a lubricant during the wear testing. The wear of steel pin as a function of nanoparticle concentration for different lubricating conditions is depicted in Fig 5(a). A reduction in wear was observed with an increase of nanoparticle concentration for monotype and hybrid nanofluid. This may be attributed to the formation of a nano-layer between the sliding surfaces of pin and disc, and intensity of layer could be enhanced by the presence of more number of nanoparticles at higher concentrations. Moreover, a higher rate of wear was observed initially, and after some time the wear rate stabilises for all the samples (Fig 5(b)). It can be seen from Fig 5(c) that Al-GnP hybrid nanofluid exhibits the highest lubricating property followed by monotype alumina nanofluid. Alumina nanofluid and base fluid produced comparable results, but significantly better than dry condition.

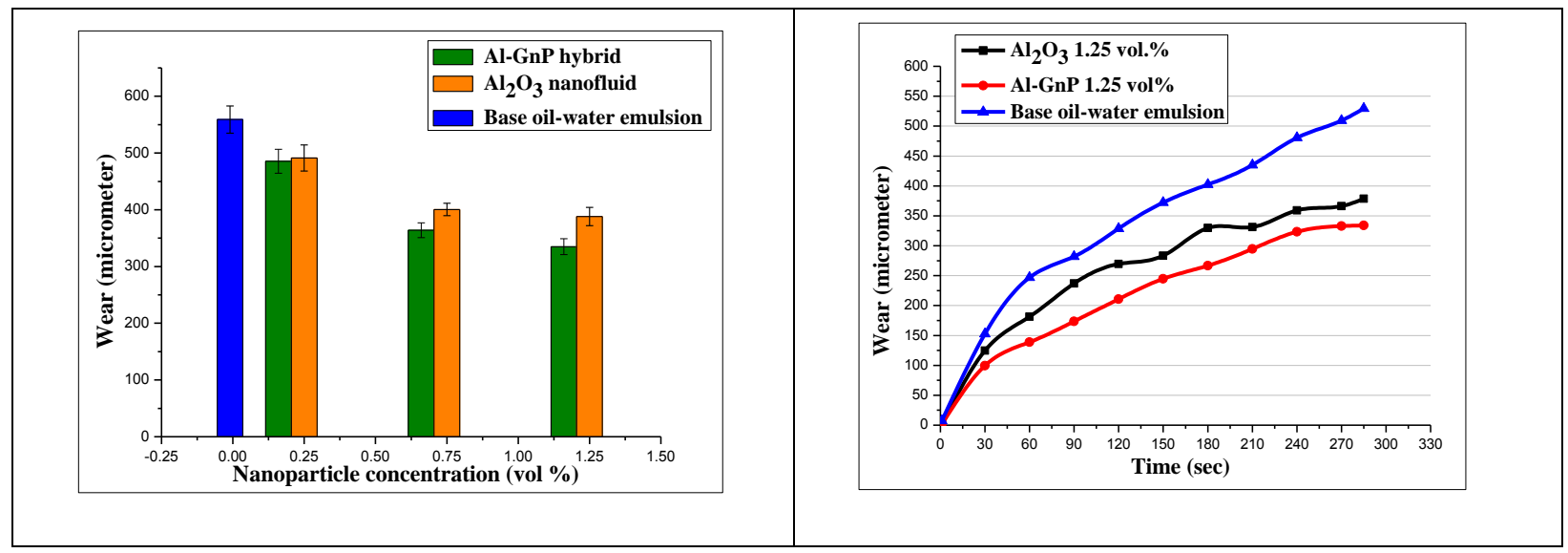




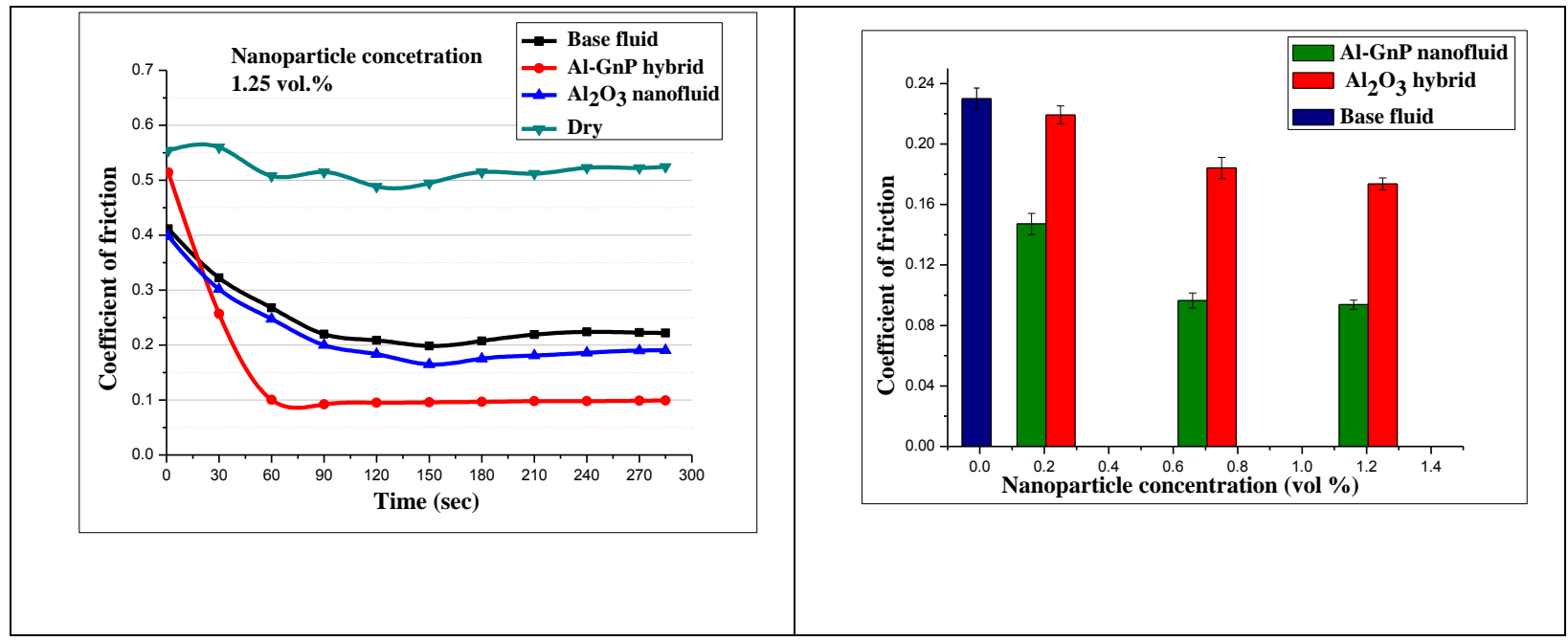

Fig 5 Wear of AISI 304 pin as a function of (a) nanoparticle concentration (b) time for different lubricating mediums (c) Coefficient of friction for different lubricating mediums w.r.t. time (d) w.r.t. nanoparticle concentration

Fig 5(d) depicts that Al-GnP hybrid nanofluid possesses the lowest coefficient of friction for all volumetric concentrations followed by monotype alumina nanofluids. As earlier stated, this may be attributed due to the formation of a nano-layer between the sliding surfaces of pin and disc. Furthermore, this reducing trend of the coefficient of friction with an increase in nanoparticle concentration has shown a reduction in the friction force.

Fig 6 presents the FESEM images of the sliding surface of the pin during the pin-on-disc experiment for various lubricating mediums at a magnification of $100 \mathrm{X}$ and $1.00 \mathrm{KX}$. A noticeable qualitative difference in the surface morphology could be seen. Moreover, it can easily be noticed that best surface quality is seen in the case of $\mathrm{Al}-\mathrm{GnP}$ hybrid nanofluid and manifested as a superior lubricating medium over monotype alumina nanofluid and base fluid.

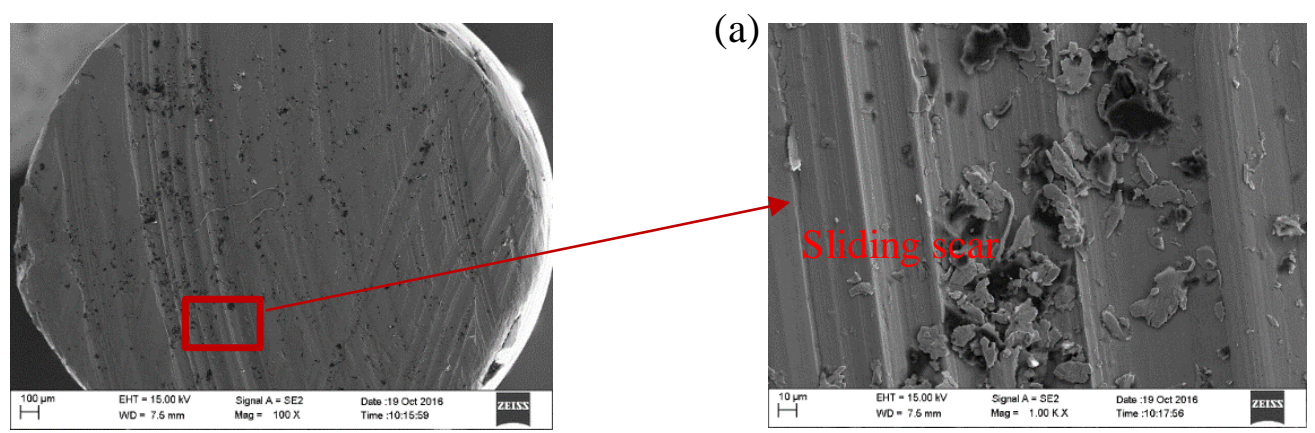




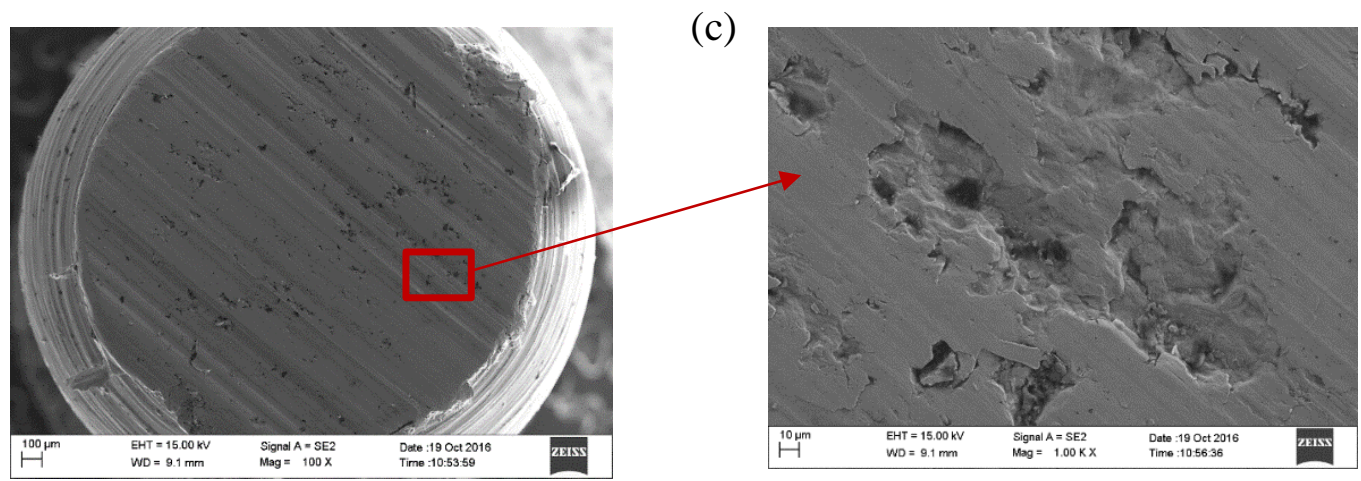

(d)

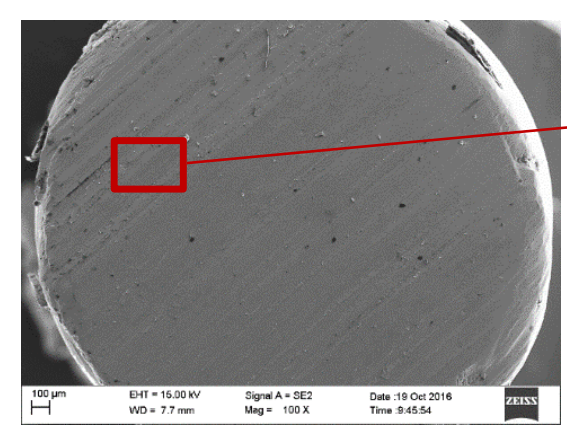

(e)

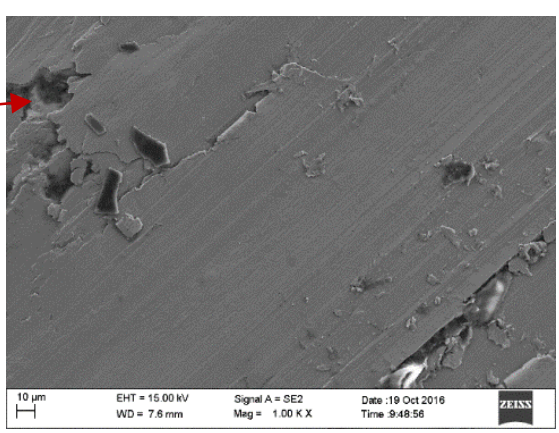

(f)

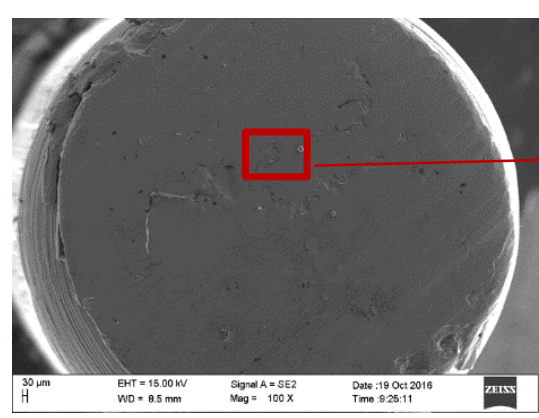

(g)

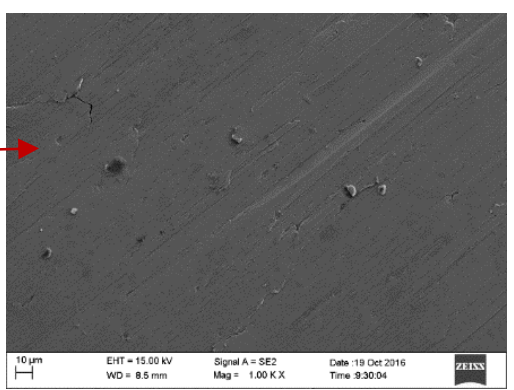

(h)

Fig 6 FESEM images of pin wear under (a-b) dry (c-d) base fluid (e-f) $\mathrm{Al}_{2} \mathrm{O}_{3}$ (g-h) Al-GNP nanofluids in pin-on-disc test

\subsection{Contact angle measurement for nano-cutting fluids}

Spreadability of cutting fluid over tool surface may enhance the heat extraction from hot tool surface. The wettability characteristics of any cutting fluid can be determined by the measurement of the contact angle between the solid surface and the droplet. 


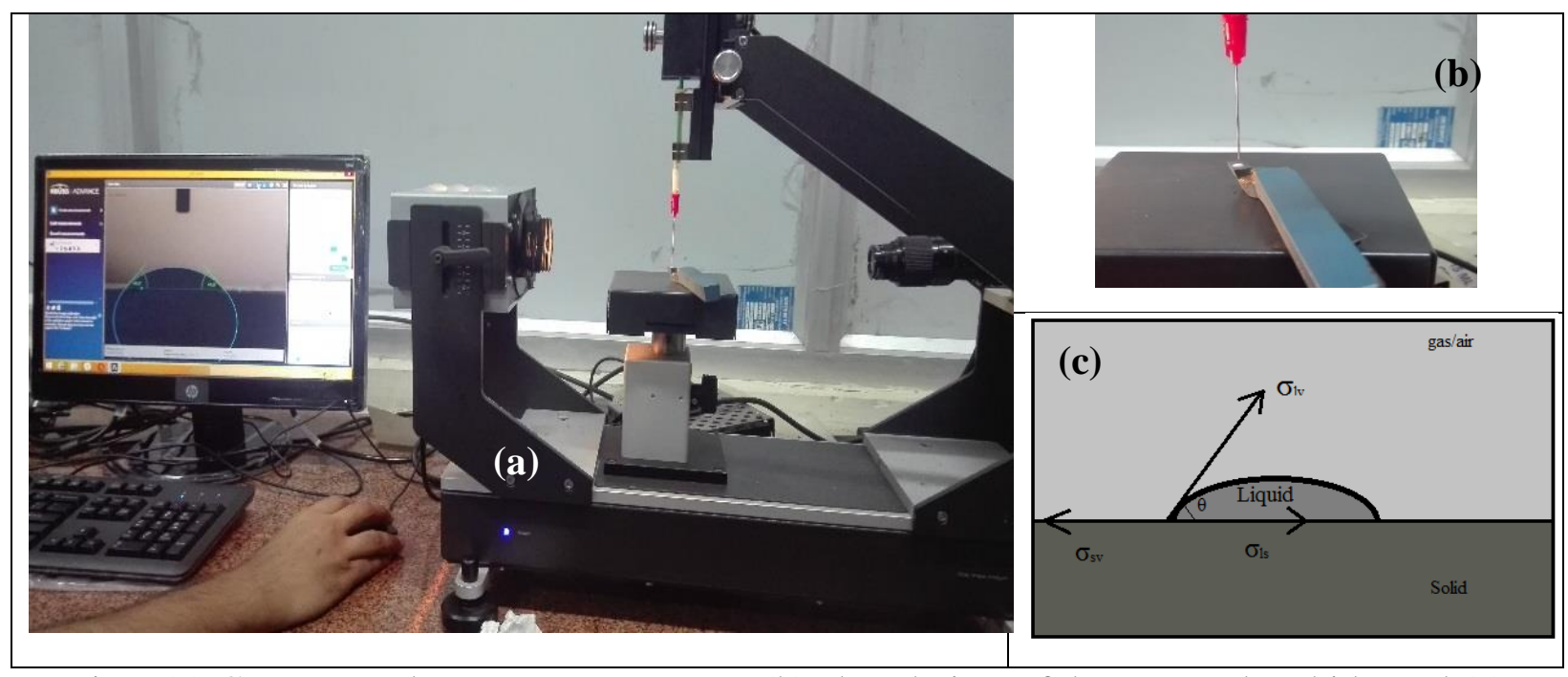

Fig 7 (a) Contact angle measurement setup (b) closed view of dropper and carbide tool (c) Schematic diagram showing a liquid droplet on solid surface

The determination of contact angle is often based on Young's (1805) contact angle equation (Eq. 1). This equation explains an equilibrium force balance at three phase (air as the third phase) interface illustrated in Fig 7(c) (Khandekar et al., 2012). The equilibrium thermodynamic contact angle is given by:

$$
\cos \theta=\frac{\sigma_{s v}-\sigma_{s l}}{\sigma_{l v}}
$$

Where $\theta$ is equilibrium contact angle, $\sigma_{\mathrm{lv}}, \sigma_{\mathrm{sv}}$ and $\sigma_{\mathrm{sl}}$ are liquid-vapour, solid-vapour, and solid-liquid interfacial tensions, respectively.

The free energy of a system depends on the intermolecular force potentials of constituent molecules/atoms which give rise to surface tension phenomenon. Also, the net surface tension of any liquid strongly depends on Van der Walls forces (Khandekar et al., 2012). These forces have interaction length scale of nanometre size, equivalent to that of nanoparticle size. So it is expected that addition of nanoparticles affects the net free energy of a pure liquid-solid-air interface. For testing this hypothesis, the spreadability of all nanofluids (nanofluids of different nanoparticle concentrations i.e. $0 \%, 0.25 \%, 0.5 \%, 0.75 \%, 1.0 \%, 1.25 \%$ and $1.5 \%$ ) was determined by the measurement of the macroscopic contact angle between the fluid droplet and cemented carbide tool insert surface. The contact angle measurement setup is illustrated in Fig 7. The measurement of contact angle $(\theta)$ was performed by using a drop shape analyzer 25 (KRUSS), with an inbuilt software DSA 4. The cutting tool (carbide insert) surface was kept in the environment chamber at 
room temperature. The chamber was allowed to come to equilibrium conditions so that a saturated relative humidity environment was established. Then, accurately measured $10 \mu 1$ cutting fluid was carefully dropped through the $0.5 \mathrm{~mm}$ OD needle tip on the top surface of the surface. The camera of the instrument was perfectly adjusted to take the drop image formed on the tool surface and contact angle data was measured by the inbuilt software.

Fig 8 clearly shows that wettability (contact angle) of nano-cutting fluid is affected significantly by the addition of nanoparticles. As nanoparticle concentration increases from $0 \%$ to $1.5 \%$, the contact angle first reduces and then it increases for higher concentrations for all nanofluids samples. This can be justified by the findings of Wasan et al. (2011) who noticed an increase in contact diameter (spreading of the droplet) with an increase of nanoparticle concentration in the conventional fluid. The smallest contact angle for Al-GnP and alumina nanofluids could be recorded as $38.9^{\circ}$ (at $1.0 \mathrm{vol} \%$ ) and $41.9^{\circ}$ (at $1.0 \mathrm{vol} \%$ ), respectively, thus, gave maximum wetting area per unit liquid volume. The contact angle for base fluid was recorded as $54.9^{\circ}$, which is much higher as compared to the contact angle measured for each nanofluid. So it improves the heat extraction and lubricating properties compared to base fluid. The findings are in good agreement with the results obtained in previous investigations (Khandekar et al., 2012, Park et al., 2011)).

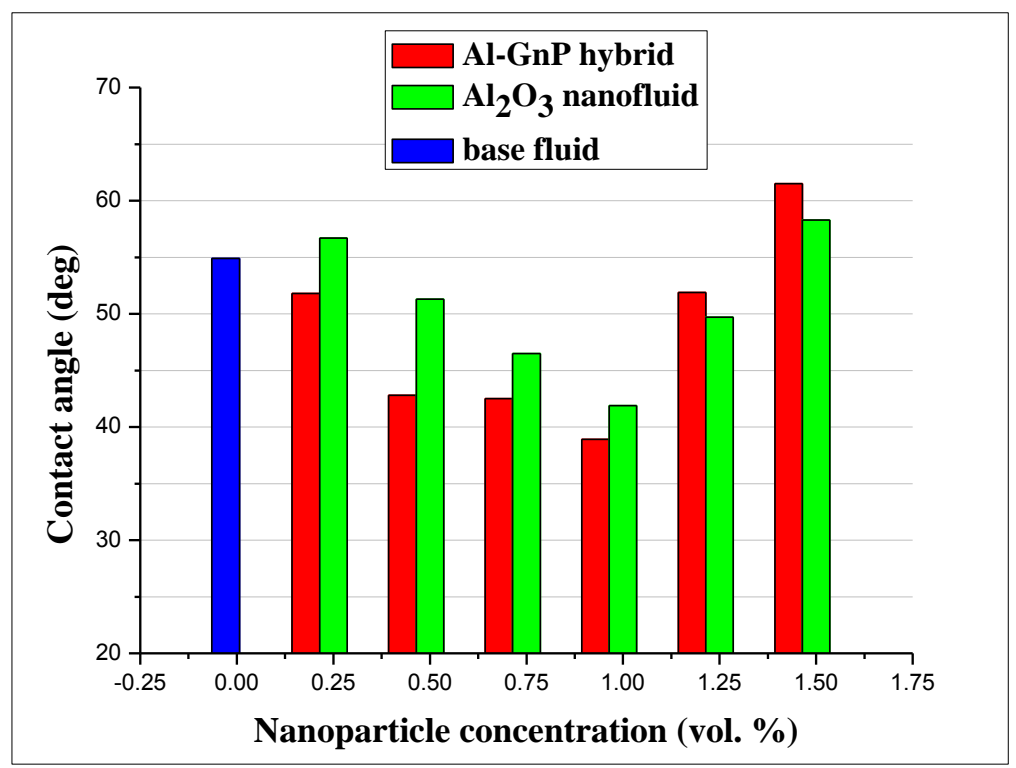

Fig 8 Contact angle as a function of nanoparticle concentration of different nanofluids 


\subsection{Experimental setup}

Turning of AISI 304 steel was carried out on HMT (model NH 22/1500) lathe machine under mist of different nanofluids using MQL technique. The pictorial view of experiment setup is shown in Fig 9. The coated cemented carbide insert (Widia's CCMT 09T304-TN2000) was mechanically clamped on a rigid tool holder (widax SCLCR1212F09 D 3J). The MQL system involves a compressor, a flow controlling unit, an air-dryer and a spray nozzle. The nanofluid flow rate and air supply pressure for MQL system are set at $2.5 \mathrm{ml} / \mathrm{min}$ and $4 \mathrm{bar}$, respectively. A discharge nozzle is placed at a distance of $5 \mathrm{~cm}$ just above the rake face of cutting tool, capable of impinging mist vertically downward on tool (Fig. 9(b)). As a result, the mist of nano-cutting fluid effectively falls in the cutting zone.
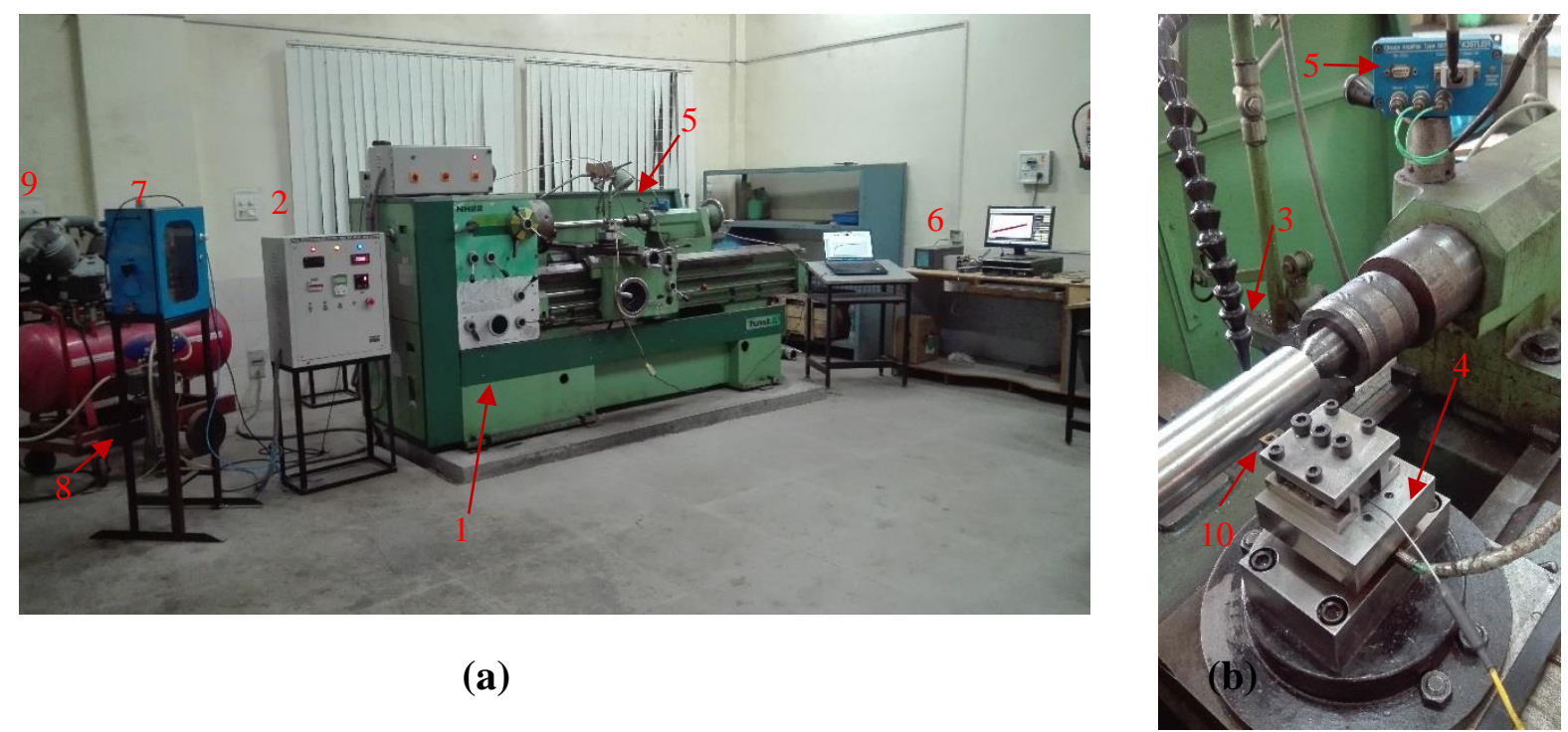

1. HMT Lathe (NH22) machine

2. Microprocessor based speed controller

3. Spray nozzle

4. Kistler force dynamometer

5. Kistler charge amplifier
6. Force display unit

7. MQL unit

8. Air dryer

9. Air compressor

10. Carbide cutting insert

Fig 9(a) Pictorial view of experimental setup (b) closed view of machining zone

All the experiments were conducted in triplicate and the average of the values was considered. Cutting forces were calculated by using three-component piezoelectric Kistler dynamometer (Type $9047 \mathrm{CNK})$. For analysis, mean values of the cutting forces were noted over a regular interval of time. The average surface roughness $\left(R_{a}\right)$ of the work piece was measured by Surftest SJ-210 (Mitutoya make) after every turning operation under different machining environments. This 
exercise was repeated at six reference points at $60^{\circ}$ angle on the cylindrical surface of the work piece. Surftest SJ-210 is a contact-type measuring instrument with a probe (having diamond tip of $2 \mu \mathrm{m}$-radius) that is able to travel on the work piece surface. The instrument has a measuring range of $360 \mu \mathrm{m}(-200 \mu \mathrm{m}$ to $160 \mu \mathrm{m})$, measuring speed of $0.25 \mathrm{~mm} / \mathrm{sec}$, probe returning speed of 1 $\mathrm{mm} / \mathrm{sec}$ and cut off length of $0.08 \mathrm{~mm}$.

\subsection{Experimental design using Response surface methodology}

Response Surface Methodology (RSM) is a collection of statistical techniques that are useful for the modeling and analysis of problems in which one or more responses of interest are influenced by several variables and has two objectives: first is to find the relationship between responses and several variables and second to optimize the responses. The first step in RSM is to find a suitable approximation for the true functional relationship between response y and a set of independent variables employed. When the independent variables change values in certain directions, the responses should also change (Montgomery, 2009). In other words, RSM tends to focus on the relationships between multiple factors $\left(x_{1}, x_{2}, x_{3}, \ldots, x_{k}\right)$ and the response $(y)$. Consequently, the functional relationship between the responses and the independent variables should first be determined to produce a proper approximating function, and then the factor setting levels needed to obtain the optimal response should be identified. The relationship between the response variables and the independent variables (factors) can be presented in the form of the following equation.

$$
y=f\left(x_{1}, x_{2}, x_{3}, \ldots \ldots \ldots x_{k}\right)
$$

Where $f$ is a multivariate function, the items represent the factors (independent variables), and the relationship describes a curved surface $y=f\left(x_{1}, x_{2}, x_{3} \ldots \ldots, x_{k}\right)$ that is known as a Response Surface.

Usually, a second order model is utilized in RSM (Gopal and Rao, 2003). A second-order model can significantly improve the optimization process when a first-order model suffers a lack of fit due to the interaction between variables and surface curvature. A general second-order model is defined as

$$
y=a_{o}+\sum_{i=1}^{n} a_{i} x_{i}+\sum_{i=1}^{n} a_{i i} x_{i}^{2}+\sum_{i=1}^{n} \sum_{j=1}^{n} a_{i j} x_{i} x_{j} \quad: i<j
$$


Where, $\mathrm{a}_{0}$ is the constant and $\mathrm{a}_{\mathrm{i}}, \mathrm{a}_{\mathrm{ii}}$ and $\mathrm{a}_{\mathrm{ij}}$ are respectively, the coefficients of first-order (linear), second-order (quadratic) and cross-product terms. The term $x_{i}$ and $x_{j}$ represent the input variables.

The input variables were optimized by RSM, using a Box-Behnken design to get the optimized value of response parameters. Box-Behnken design has three levels (low, medium, and high, coded as $-1,0$, and +1 ) and needs fewer experimental runs and less time. A total number of 27 trials including three center points were employed. All the experiments were performed independently in triplicates, and the average values were presented as the response. The process variable (input machining parameters) with their values on different levels are listed in Table 1. The Design Expert 10.0 was applied for the Box-Behnken experimental design, regression analysis of the experimental data, quadratic model buildings and also to plot three-dimensional response surface plots. Statistical analysis of the models was used to evaluate the analysis of variance (ANOVA). The quality of fit the second-order polynomial model equation was judged statistically via the coefficient of determination $\mathrm{R}^{2}$ and the adjusted $\mathrm{R}^{2}$. The fitted polynomial equation was then expressed regarding three-dimensional surface plots to evaluate the relationship between the responses and visualize the interaction between the variables utilized in the study. The point optimization method was conducted to optimize the level of each variable for a desirable response. The combination of different optimized input variables, which yielded the desired value of the response, was determined in an attempt to verify the validity of the model. At last, validation experiments were performed to check the adequacy of the experimental setup.

Table $1 \quad$ Control factors and their levels

\begin{tabular}{lccccc}
\hline Control factor & Symbol & Units & Level 1 & Level 2 & Level 3 \\
\hline Cutting speed & $\mathrm{V}$ & $\mathrm{m} / \mathrm{min}$ & 60 & 90 & 120 \\
Cutting feed & $\mathrm{F}$ & $\mathrm{mm} / \mathrm{rev}$ & 0.08 & 0.12 & 0.16 \\
$\begin{array}{l}\text { Depth of cut } \\
\text { Nanoparticle }\end{array}$ & $\mathrm{D}$ & $\mathrm{mm}$ & 0.6 & 0.9 & 1.2 \\
concentration & $\mathrm{Np}$ & $\mathrm{vol} \%$ & 0.25 & 0.75 & 1.25 \\
\hline
\end{tabular}

Table 2 summarizes the design of experiment with experimental run order and output in the terms of four response parameters for alumina based nanofluid and Al-GnP hybrid nanofluid. Table 2 Machining variables and response parameters 


\begin{tabular}{|c|c|c|c|c|c|c|c|c|c|c|c|c|}
\hline \multirow{3}{*}{ Run } & \multirow{2}{*}{\multicolumn{4}{|c|}{ Input Machining parameters }} & \multicolumn{4}{|c|}{ Response variables } & & & & \\
\hline & & & & & \multicolumn{4}{|c|}{ Alumina nanofluid } & \multicolumn{4}{|c|}{ Al-GnP hybrid nanofluid } \\
\hline & $\begin{array}{c}\mathrm{V} \\
(\mathrm{m} / \mathrm{min})\end{array}$ & $\begin{array}{c}\mathrm{f} \\
(\mathrm{mm} / \mathrm{rev})\end{array}$ & $\begin{array}{c}\mathrm{d} \\
(\mathrm{mm})\end{array}$ & $\begin{array}{c}\mathrm{np} \\
\text { (vol.\%) }\end{array}$ & $\mathrm{F}_{\mathrm{z}}(\mathrm{N})$ & $\mathrm{F}_{\mathrm{y}}(\mathrm{N})$ & $\mathrm{F}_{\mathrm{x}}(\mathrm{N})$ & $\begin{array}{c}\mathrm{R}_{\mathrm{a}} \\
(\mu \mathrm{m})\end{array}$ & $\mathrm{F}_{\mathrm{z}}(\mathrm{N})$ & $\mathrm{F}_{\mathrm{y}}(\mathrm{N})$ & $\mathrm{F}_{\mathrm{x}}(\mathrm{N})$ & $\begin{array}{c}\mathrm{R}_{\mathrm{a}} \\
(\mu \mathrm{m})\end{array}$ \\
\hline 1 & 90 & 0.16 & 1.2 & 0.75 & 527.275 & 287.955 & 103.296 & 2.712 & 481.425 & 259.965 & 98.1 & 2.169 \\
\hline 2 & 60 & 0.12 & 1.2 & 0.75 & 475.335 & 259.26 & 94.389 & 2.367 & 434 & 234.128 & 88.35 & 1.893 \\
\hline 3 & 120 & 0.12 & 0.9 & 1.25 & 314.111 & 240.305 & 76.872 & 1.474 & 340.673 & 241.76 & 91.23 & 1.179 \\
\hline 4 & 60 & 0.12 & 0.6 & 0.75 & 256.83 & 181.665 & 56.955 & 2.234 & 217 & 164.009 & 61.89 & 1.787 \\
\hline 5 & 90 & 0.12 & 0.9 & 0.75 & 361.039 & 222.605 & 74.799 & 1.978 & 329.647 & 200.976 & 75.84 & 1.582 \\
\hline 6 & 60 & 0.12 & 0.9 & 0.25 & 444.668 & 243.62 & 89.136 & 2.456 & 406 & 238.023 & 89.82 & 1.995 \\
\hline 7 & 120 & 0.12 & 1.2 & 0.75 & 479.339 & 292.275 & 95.082 & 1.823 & 317.24 & 263.861 & 99.57 & 1.458 \\
\hline 8 & 120 & 0.08 & 0.9 & 0.75 & 241.584 & 217.98 & 54.363 & 1.568 & 236.67 & 196.286 & 74.07 & 1.435 \\
\hline 9 & 90 & 0.08 & 1.2 & 0.75 & 350.378 & 218.465 & 72.969 & 1.656 & 311.346 & 197.239 & 74.43 & 1.325 \\
\hline 10 & 60 & 0.08 & 0.9 & 0.75 & 260.687 & 174.92 & 62.802 & 1.824 & 242.55 & 157.887 & 59.58 & 1.459 \\
\hline 11 & 90 & 0.12 & 0.9 & 0.75 & 347.774 & 217.415 & 72.525 & 1.945 & 317.52 & 196.286 & 74.07 & 1.556 \\
\hline 12 & 120 & 0.12 & 0.9 & 0.25 & 395.178 & 221.66 & 82.032 & 1.856 & 340.97 & 200.101 & 75.51 & 1.548 \\
\hline 13 & 90 & 0.12 & 1.2 & 1.25 & 464.884 & 247.205 & 92.619 & 1.901 & 424.462 & 232.22 & 87.63 & 1.220 \\
\hline 14 & 90 & 0.12 & 0.9 & 0.75 & 381.591 & 230.725 & 78.462 & 1.911 & 348.39 & 208.29 & 78.6 & 1.528 \\
\hline 15 & 60 & 0.16 & 0.9 & 0.75 & 441.945 & 254.43 & 88.659 & 2.973 & 403.515 & 215.604 & 81.36 & 2.378 \\
\hline 16 & 120 & 0.12 & 0.6 & 0.75 & 173.075 & 148.785 & 42.576 & 1.899 & 158.025 & 134.275 & 50.67 & 1.652 \\
\hline 17 & 90 & 0.12 & 0.6 & 0.25 & 218.995 & 166.87 & 50.439 & 2.034 & 199.92 & 150.653 & 56.85 & 1.627 \\
\hline 18 & 90 & 0.08 & 0.6 & 0.75 & 138.866 & 95.415 & 36.702 & 1.611 & 126.787 & 86.0985 & 32.49 & 1.288 \\
\hline 19 & 90 & 0.08 & 0.9 & 0.25 & 297.045 & 197.475 & 63.825 & 2.197 & 271.215 & 178.319 & 67.29 & 1.757 \\
\hline 20 & 90 & 0.08 & 0.9 & 1.25 & 253.575 & 180.415 & 56.388 & 1.527 & 231.525 & 162.896 & 61.47 & 1.222 \\
\hline 21 & 60 & 0.12 & 0.9 & 1.25 & 335.685 & 195.16 & 69.441 & 2.116 & 306.495 & 191.993 & 72.45 & 1.692 \\
\hline 22 & 90 & 0.12 & 1.2 & 0.25 & 484.204 & 271.07 & 95.919 & 2.111 & 442.103 & 244.701 & 92.34 & 1.689 \\
\hline 23 & 90 & 0.12 & 0.6 & 1.25 & 199.234 & 159.06 & 47.046 & 1.899 & 181.912 & 127.677 & 48.18 & 1.419 \\
\hline 24 & 90 & 0.16 & 0.6 & 0.75 & 236.684 & 173.775 & 53.469 & 2.656 & 216.09 & 156.854 & 59.19 & 2.125 \\
\hline 25 & 90 & 0.16 & 0.9 & 1.25 & 412.965 & 243.08 & 83.775 & 2.455 & 377.055 & 219.42 & 82.8 & 1.764 \\
\hline 26 & 90 & 0.16 & 0.9 & 0.25 & 449.211 & 257.27 & 89.922 & 2.745 & 410.13 & 232.299 & 87.66 & 2.196 \\
\hline 27 & 120 & 0.16 & 0.9 & 0.75 & 435.785 & 276.065 & 84.102 & 2.499 & 397.72 & 245.718 & 92.95 & 1.849 \\
\hline
\end{tabular}

\section{Results and discussion}

\subsection{Machining with alumina nanoparticle mixed cutting fluid}

The variance analysis of response parameters was made with the objective of analysing the influence of nanoparticle inclusion on the obtained results. Table 3-6 show the results of ANOVA, respectively for $F_{z}, F_{y}, F_{x}$, and $R_{a}$. This analysis was carried out at a confidence level of $95 \%$ (i.e. $5 \%$ significance level). The last column of these tables show the influence of variation in input variables (significant or non-significant) on response parameter (output). Table 3 shows that $\mathrm{V}, \mathrm{f}$, $\mathrm{d}$ and $\mathrm{np}$ all have significant effect on the cutting force. It can be depicted from Tables 4-5 that $\mathrm{np}$ 
and its interaction with speed have a significant effect on thrust force and feed force. Table 6 clearly reveals that feed is the most significant factor associated with surface roughness, because its increase generates helicoids and these helicoids become broader and deeper with the increase of feed rate. Similar findings were observed by Bouacha et al. (2010) in their investigations.

Table 3 ANOVA table of cutting force $\left(\mathrm{F}_{\mathrm{z}}\right)$ for $\mathrm{Al}_{2} \mathrm{O}_{3}$ nanofluid

\begin{tabular}{lrrrrr}
\hline Source & $\begin{array}{r}\text { Sum of } \\
\text { Squares }\end{array}$ & DF & Mean Square & F-value & Prob. \\
\hline Model & 301500 & 14 & 21538.93 & 45.32 & $<0.0001$ \\
A-V & 2583.62 & 1 & 2583.62 & 5.44 & 0.0380 \\
B-f & 77077.05 & 1 & 77077.05 & 162.16 & $<0.0001$ \\
C-d & 202200 & 1 & 202200 & 425.43 & $<0.0001$ \\
D-np & 7948.87 & 1 & 7948.87 & 16.72 & 0.0015 \\
AB & 41.88 & 1 & 41.88 & 0.088 & 0.7717 \\
AC & 1925.41 & 1 & 1925.41 & 4.05 & 0.0671 \\
AD & 194.83 & 1 & 194.83 & 0.41 & 0.5341 \\
BC & 1563.37 & 1 & 1563.37 & 3.29 & 0.0948 \\
BD & 13.05 & 1 & 13.05 & 0.027 & 0.8712 \\
CD & 0.049 & 1 & 0.049 & 10230 & 0.9921 \\
$\mathrm{~A}^{2}$ & 119.31 & 1 & 119.31 & 0.25 & 0.6254 \\
$\mathrm{~B}^{2}$ & 2419.24 & 1 & 2419.24 & 5.09 & 0.0435 \\
$\mathrm{C}^{2}$ & 3720.14 & 1 & 3720.14 & 7.83 & 0.0161 \\
$\mathrm{D}^{2}$ & 237.37 & 1 & 237.37 & 0.50 & 0.4933 \\
Residual & 5703.66 & 12 & 475.30 & & \\
Lack of Fit & 5123.01 & 10 & 512.30 & 1.76 & 0.4154 \\
Pure Error & 580.64 & 2 & 290.32 & & \\
Cor Total & 307200 & 26 & & & \\
\hline
\end{tabular}

Table 4 ANOVA table of thrust force $\left(\mathrm{F}_{\mathrm{y}}\right)$ for $\mathrm{Al}_{2} \mathrm{O}_{3}$ nanofluid

\begin{tabular}{lrrrrr}
\hline Source & $\begin{array}{r}\text { Sum of } \\
\text { Squares }\end{array}$ & DF & Mean Square & F-value & Prob. \\
\hline Model & 55784.08 & 14 & 3984.58 & 29.74 & $<0.0001$ \\
A-V & 645.55 & 1 & 645.55 & 4.82 & 0.0486 \\
B-f & 13865.54 & 1 & 13865.54 & 103.48 & $<0.0001$ \\
C-d & 35279.87 & 1 & 35279.87 & 263.29 & $<0.0001$ \\
D-np & 716.73 & 1 & 716.73 & 5.35 & 0.0393 \\
AB & 114.76 & 1 & 114.76 & 0.86 & 0.3730 \\
AC & 1085.54 & 1 & 1085.54 & 8.10 & 0.0147 \\
AD & 1125.77 & 1 & 1125.77 & 8.40 & 0.0134 \\
BC & 19.67 & 1 & 19.67 & 0.15 & 0.7083 \\
BD & 2.06 & 1 & 2.06 & 0.015 & 0.9034 \\
CD & 64.44 & 1 & 64.44 & 0.48 & 0.5012 \\
$\mathrm{~A}^{2}$ & 495.00 & 1 & 495.00 & 3.69 & 0.0787 \\
$\mathrm{~B}^{2}$ & 223.68 & 1 & 223.68 & 1.67 & 0.2207 \\
$\mathrm{C}^{2}$ & 1349.45 & 1 & 1349.45 & 10.07 & 0.0080 \\
$\mathrm{D}^{2}$ & 2.86 & 1 & 2.86 & 0.021 & 0.8862 \\
Residual & 1607.96 & 12 & 134.00 & & \\
Lack of Fit & 1517.95 & 10 & 151.79 & 3.37 & 0.2503 \\
Pure Error & 90.01 & 2 & 45.00 & & \\
Cor Total & 57392.03 & 26 & & & \\
\hline
\end{tabular}

Table 5 ANOVA table of feed force $\left(\mathrm{F}_{\mathrm{x}}\right)$ for $\mathrm{Al}_{2} \mathrm{O}_{3}$ nanofluid

\begin{tabular}{lrrrrrr}
\hline Source & $\begin{array}{r}\text { Sum of } \\
\text { Squares }\end{array}$ & DF & Mean Square & F-value & Prob. \\
\hline Model & 8713.82 & 14 & 622.42 & 68.48 & $<0.0001$ \\
\hline
\end{tabular}




\begin{tabular}{lrrrrr}
\hline A-V & 57.88 & 1 & 57.88 & 6.37 & 0.0267 \\
B-f & 2032.53 & 1 & 2032.53 & 223.63 & $<0.0001$ \\
C-d & 5944.62 & 1 & 5944.62 & 654.07 & $<0.0001$ \\
D-np & 169.74 & 1 & 169.74 & 18.68 & 0.0010 \\
AB & 3.77 & 1 & 3.77 & 0.41 & 0.5318 \\
AC & 56.79 & 1 & 56.79 & 6.25 & 0.0279 \\
AD & 52.82 & 1 & 52.82 & 5.81 & 0.0329 \\
BC & 45.97 & 1 & 45.97 & 5.06 & 0.0441 \\
BD & 0.42 & 1 & 0.42 & 0.046 & 0.8342 \\
CD & 2162 & 1 & 2162 & 23790 & 0.9879 \\
$\mathrm{~A}^{2}$ & 17.36 & 1 & 17.36 & 1.91 & 0.1921 \\
$\mathrm{~B}^{2}$ & 83.75 & 1 & 83.75 & 9.21 & 0.0104 \\
$\mathrm{C}^{2}$ & 136.78 & 1 & 136.78 & 15.05 & 0.0022 \\
$\mathrm{D}^{2}$ & 19.87 & 1 & 19.87 & 2.19 & 0.1650 \\
Residual & 109.06 & 12 & 9.09 & & \\
Lack of Fit & 91.12 & 10 & 9.11 & 1.02 & 0.5930 \\
Pure Error & 17.95 & 2 & 8.97 & & \\
Cor Total & 8822.89 & 26 & & & \\
\hline
\end{tabular}

Table 6 ANOVA table of surface roughness $\left(\mathrm{R}_{\mathrm{a}}\right)$ for $\mathrm{Al}_{2} \mathrm{O}_{3}$ nanofluid

\begin{tabular}{lrrrrr}
\hline Source & $\begin{array}{r}\text { Sum of } \\
\text { Squares }\end{array}$ & DF & Mean Square & F-value & Prob. \\
\hline Model & 4.04 & 14 & 0.29 & 19.21 & $<0.0001$ \\
A-V & 0.68 & 1 & 0.68 & 45.08 & $<0.0001$ \\
B-f & 2.67 & 1 & 2.67 & 177.47 & $<0.0001$ \\
C-d & 4681 & 1 & 4681 & 0.31 & 0.5870 \\
D-np & 0.34 & 1 & 0.34 & 22.79 & 0.0005 \\
AB & 0.012 & 1 & 0.012 & 0.79 & 0.3914 \\
AC & 0.011 & 1 & 0.011 & 0.73 & 0.4106 \\
AD & 44100 & 1 & 44100 & 0.029 & 0.8668 \\
BC & 302500 & 1 & 302500 & 2013 & 0.9650 \\
BD & 0.036 & 1 & 0.036 & 2.40 & 0.1471 \\
CD & 1406 & 1 & 1406 & 0.094 & 0.7649 \\
$\mathrm{~A}^{2}$ & 0.017 & 1 & 0.017 & 1.10 & 0.3143 \\
$\mathrm{~B}^{2}$ & 0.26 & 1 & 0.26 & 17.57 & 0.0012 \\
$\mathrm{C}^{2}$ & 5633 & 1 & 5633 & 0.37 & 0.5518 \\
$\mathrm{D}^{2}$ & 1365 & 1 & 1365 & 0.091 & 0.7682 \\
Residual & 0.18 & 12 & 0.015 & & \\
Lack of Fit & 0.18 & 10 & 0.018 & 15.87 & 0.0607 \\
Pure Error & 2245 & 2 & 1122 & & \\
Cor Total & 4.22 & 26 & & & \\
\hline
\end{tabular}

The relationship between input variables and response parameters are modelled by quadratic regression. The regression models of cutting force $\left(\mathrm{F}_{\mathrm{z}}\right)$, feed force $\left(\mathrm{F}_{\mathrm{y}}\right)$, thrust force $\left(\mathrm{F}_{\mathrm{x}}\right)$, and the surface roughness $\left(R_{a}\right)$ with coefficient of determination $\left(R^{2}\right)$ and adjusted $R^{2}$ equal to $98.14,97.2$, 98.76, 95.73, and 95.98, 93.93, 97.32, 90.75, respectively, are given below in Eq. 2-5. 


$$
\begin{aligned}
& F_{z}=-111.038-4.30154 * V+3405.18 * f+543.271 * d-144.874 * n p+2.69646 * \\
& V * f+2.43775 * V * d+0.465267 * V * n p+1647.48 * f * d+90.3 * f * n p+0.735 * \\
& d * n p+0.00525519 * V^{2}-13311.3 * f^{2}-293.452 * d^{2}+26.6852 * n p^{2} \\
& F_{y}=-27.0986-3.63287 * V+2362.33 * f+376.378 * d-91.9392 * n p-4.46354 * \\
& V * f+1.83042 * V * d+1.11842 * V * n p-184.792 * f * d+35.875 * f * n p- \\
& 26.7583 * d * n p+0.0107044 * V^{2}-4047.53 * f^{2}-176.741 * d^{2}-2.93167 * n p^{2} \\
& F_{x}=12.0813-1.08962 * V+580.644 * f+103.777 * d-42.979 * n p+0.80875 * V * f+ \\
& 0.418667 * V * d+0.24225 * V * n p+282.5 * f * d+16.125 * f * n p+0.155 * d * n p+ \\
& 0.00200486 * V^{2}-2476.72 * f^{2}-56.2681 * d^{2}+7.72 * n p^{2} \\
& R_{a}=3.62992-0.00786944 * V-21.2708 * f+0.00458333 * d-0.828333 * n p- \\
& 0.0454167 * V * f-0.00580556 * V * d-0.0007 * V * n p+0.229167 * f * d+4.75 * \\
& f * n p-0.125 * d * n p+0.0000619444 * V^{2}+139.062 * f^{2}+0.361111 * d^{2}+0.064 * \\
& n p^{2}
\end{aligned}
$$

In order to investigate the influence of nanoparticle concentration on various response variables, response surfaces are drawn in Fig 10. Figs 10(a-b) show that lowest cutting forces were recorded with the combination of highest nanoparticle concentration and lowest feed rate, and highest concentration and lowest depth of cut, respectively as reported by earlier researchers. Furthermore, Fig 10(c) shows the estimated responses surface for $R_{a}$ in relation to nanoparticle concentration and cutting speed, while the feed and depth of cut are kept at middle level. The lowest surface roughness was achieved with a combination of highest nanoparticle concentration and highest cutting speed. It can be deduced from Fig 10(d) that lowest roughness was achieved with a combination of highest nanoparticle concentration and lowest feed rate. 


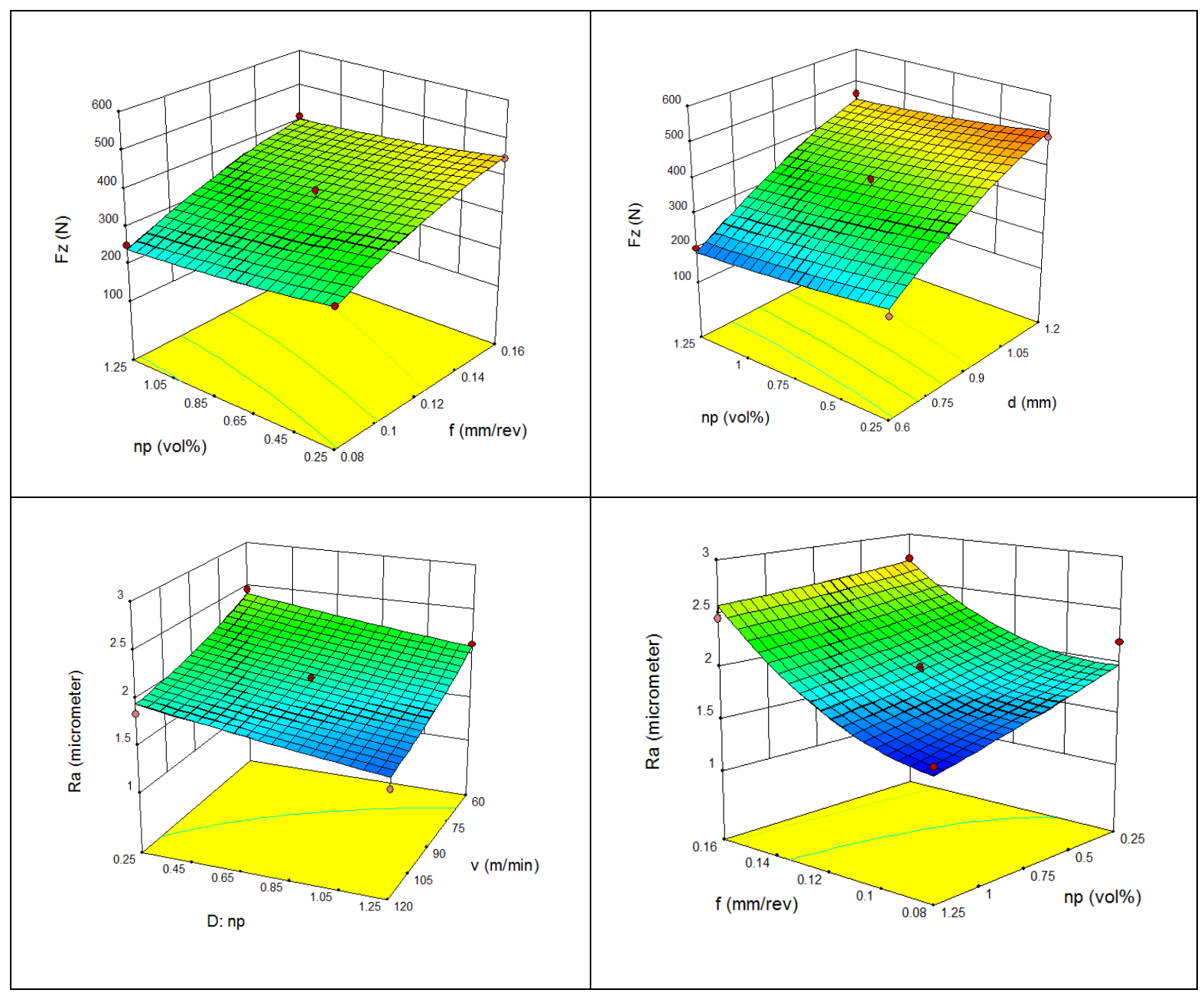

Fig. 10 Estimated response surface plots for $\mathrm{Al}_{2} \mathrm{O}_{3}$ nanoparticle concentration (np) versus v, f, and $\mathrm{d}$

\subsection{Machining with Alumina-graphene hybrid nanofluid}

Tables 7-10 show the results of ANOVA, respectively for $F_{z}, F_{y}, F_{x}$, and $R_{a}$. This analysis was carried out at a confidence level of 95\% (i.e. 5\% significance level). The last column of these tables show the influence of variation in input variables (significant or non-significant) on response parameters (output). Table 7 show that np has a significant effect on cutting force. It can be seen from Tables 8-9 that np and its interaction with speed affect thrust and feed force significantly. In case of surface roughness, np has a significant effect but depth of cut does not affect roughness significantly as shown in Table 10. The findings are in the agreement with the results of investigations carried out by Dureja et al. (2009). 
Table 7 ANOVA table of cutting force $\left(\mathrm{F}_{\mathrm{z}}\right)$ for Al-GNP hybrid nanofluid

\begin{tabular}{lrrrrr}
\hline Source & $\begin{array}{r}\text { Sum of } \\
\text { Squares }\end{array}$ & DF & $\begin{array}{r}\text { Mean } \\
\text { Square }\end{array}$ & F-value & Prob. \\
\hline Model & 229400 & 14 & 16388.96 & 20.06 & $<0.0001$ \\
A-V & 3969.88 & 1 & 3969.88 & 4.86 & 0.0477 \\
B-f & 62473.46 & 1 & 62473.46 & 76.48 & $<0.0001$ \\
C-d & 128600 & 1 & 128600 & 157.45 & $<0.0001$ \\
D-np & 4930.83 & 1 & 4930.83 & 6.04 & 0.0302 \\
AB & 1806 & 1 & 1806 & 2211000 & 0.9988 \\
AC & 834.78 & 1 & 834.78 & 1.02 & 0.3320 \\
AD & 2460.53 & 1 & 2460.53 & 3.01 & 0.1082 \\
BC & 1631.21 & 1 & 1631.21 & 2.00 & 0.1830 \\
BD & 10.94 & 1 & 10.94 & 0.013 & 0.9098 \\
CD & 45.02 & 1 & 45.02 & 0.055 & 0.8184 \\
$\mathrm{~A}^{2}$ & 191.37 & 1 & 191.37 & 0.23 & 0.6371 \\
$\mathrm{~B}^{2}$ & 1738.62 & 1 & 1738.62 & 2.13 & 0.1703 \\
$\mathrm{C}^{2}$ & 8305.53 & 1 & 8305.53 & 10.17 & 0.0078 \\
$\mathrm{D}^{2}$ & 1212.63 & 1 & 1212.63 & 1.48 & 0.2465 \\
Residual & 9802.32 & 12 & 816.86 & & \\
Lack of Fit & 9318.55 & 10 & 931.85 & 3.85 & 0.2236 \\
Pure Error & 483.77 & 2 & 241.89 & & \\
Cor Total & 239200 & 26 & & & \\
\hline
\end{tabular}

Table 8 ANOVA table of thrust force $\left(\mathrm{F}_{\mathrm{y}}\right)$ for Al-GNP hybrid nanofluid

\begin{tabular}{lrrrrr}
\hline Source & $\begin{array}{r}\text { Sum of } \\
\text { Squares }\end{array}$ & DF & $\begin{array}{r}\text { Mean } \\
\text { Square }\end{array}$ & F-value & Prob. \\
\hline Model & 49291.60 & 14 & 3520.83 & 32.81 & $<0.0001$ \\
A-V & 538.12 & 1 & 538.12 & 5.01 & 0.0449 \\
B-f & 10274.65 & 1 & 10274.65 & 95.74 & $<0.0001$ \\
C-d & 28374.72 & 1 & 28374.72 & 264.40 & $<0.0001$ \\
D-np & 614.55 & 1 & 614.55 & 5.73 & 0.0339 \\
AB & 17.16 & 1 & 17.16 & 0.16 & 0.6963 \\
AC & 884.05 & 1 & 884.05 & 8.24 & 0.0141 \\
AD & 1922.32 & 1 & 1922.32 & 17.91 & 0.0012 \\
BC & 16.12 & 1 & 16.12 & 0.15 & 0.7051 \\
BD & 1.62 & 1 & 1.62 & 0.015 & 0.9043 \\
CD & 0.022 & 1 & 0.022 & 20940 & 0.9887 \\
$\mathrm{~A}^{2}$ & 649.06 & 1 & 649.06 & 6.05 & 0.0301 \\
$\mathrm{~B}^{2}$ & 673.91 & 1 & 673.91 & 6.28 & 0.0276 \\
$\mathrm{C}^{2}$ & 1445.24 & 1 & 1445.24 & 13.47 & 0.0032 \\
$\mathrm{D}^{2}$ & 142.05 & 1 & 142.05 & 1.32 & 0.2723 \\
Residual & 1287.81 & 12 & 107.32 & & \\
Lack of Fit & 1214.61 & 10 & 121.46 & 3.32 & 0.2537 \\
Pure Error & 73.20 & 2 & 36.60 & & \\
Cor Total & 50579.42 & 26 & & & \\
\hline
\end{tabular}

Table 9 ANOVA table of feed force $\left(\mathrm{F}_{\mathrm{x}}\right)$ for Al-GNP hybrid nanofluid

\begin{tabular}{lrlrll}
\hline Source & $\begin{array}{r}\text { Sum of } \\
\text { Squares }\end{array}$ & DF & $\begin{array}{r}\text { Mean } \\
\text { Square }\end{array}$ & F-value & Prob. \\
\hline
\end{tabular}




\begin{tabular}{lrrrrr}
\hline Model & 7025.91 & 14 & 501.85 & 32.58 & $<0.0001$ \\
$\mathrm{~A}-\mathrm{V}$ & 77.78 & 1 & 77.78 & 5.05 & 0.0442 \\
$\mathrm{~B}-\mathrm{f}$ & 1468.10 & 1 & 1468.10 & 95.32 & $<0.0001$ \\
$\mathrm{C}-\mathrm{d}$ & 4039.54 & 1 & 4039.54 & 262.28 & $<0.0001$ \\
$\mathrm{D}-\mathrm{np}$ & 87.41 & 1 & 87.41 & 5.68 & 0.0346 \\
$\mathrm{AB}$ & 2.10 & 1 & 2.10 & 0.14 & 0.7182 \\
$\mathrm{AC}$ & 125.89 & 1 & 125.89 & 8.17 & 0.0144 \\
$\mathrm{AD}$ & 273.74 & 1 & 273.74 & 17.77 & 0.0012 \\
$\mathrm{BC}$ & 2.30 & 1 & 2.30 & 0.15 & 0.7062 \\
$\mathrm{BD}$ & 0.23 & 1 & 0.23 & 0.015 & 0.9047 \\
$\mathrm{CD}$ & 1970 & 1 & 1970 & 12790 & 0.9912 \\
$\mathrm{~A}^{2}$ & 93.27 & 1 & 93.27 & 6.06 & 0.0300 \\
$\mathrm{~B}^{2}$ & 95.10 & 1 & 95.10 & 6.17 & 0.0287 \\
$\mathrm{C}^{2}$ & 206.67 & 1 & 206.67 & 13.42 & 0.0032 \\
$\mathrm{D}^{2}$ & 19.99 & 1 & 19.99 & 1.30 & 0.2768 \\
Residual & 184.82 & 12 & 15.40 & & \\
Lack of Fit & 174.39 & 10 & 17.44 & 3.35 & 0.2519 \\
Pure Error & 10.42 & 2 & 5.21 & & \\
Cor Total & 7210.73 & 26 & & & \\
\hline
\end{tabular}

Table 10 ANOVA table of surface roughness $\left(\mathrm{R}_{\mathrm{a}}\right)$ for Al-GNP hybrid nanofluid

\begin{tabular}{lrrrrr}
\hline Source & $\begin{array}{r}\text { Sum of } \\
\text { Squares }\end{array}$ & DF & $\begin{array}{r}\text { Mean } \\
\text { Square }\end{array}$ & F-value & Prob. \\
\hline Model & 2.50 & 14 & 0.18 & 16.84 & $<0.0001$ \\
A-V & 0.36 & 1 & 0.36 & 34.16 & $<0.0001$ \\
B-f & 1.33 & 1 & 1.33 & 125.68 & $<0.0001$ \\
C-d & 9607000 & 1 & 9607000 & 90750 & 0.9765 \\
D-np & 0.46 & 1 & 0.46 & 43.68 & $<0.0001$ \\
AB & 0.064 & 1 & 0.064 & 6.02 & 0.0304 \\
AC & 0.022 & 1 & 0.022 & 2.12 & 0.1715 \\
AD & $1.110 \mathrm{E}-003$ & 1 & $1.110 \mathrm{E}-003$ & 0.10 & 0.7516 \\
BC & $1.600 \mathrm{E}-005$ & 1 & $1.600 \mathrm{E}-005$ & $1.511 \mathrm{E}-003$ & 0.9696 \\
BD & $2.662 \mathrm{E}-003$ & 1 & $2.662 \mathrm{E}-003$ & 0.25 & 0.6251 \\
CD & 0.027 & 1 & 0.027 & 2.56 & 0.1358 \\
$\mathrm{~A}^{2}$ & 0.046 & 1 & 0.046 & 4.32 & 0.0598 \\
$\mathrm{~B}^{2}$ & 0.16 & 1 & 0.16 & 15.31 & 0.0021 \\
$\mathrm{C}^{2}$ & $3.143 \mathrm{E}-003$ & 1 & $3.143 \mathrm{E}-003$ & 0.30 & 0.5958 \\
$\mathrm{D}^{2}$ & $3.185 \mathrm{E}-003$ & 1 & $3.185 \mathrm{E}-003$ & 0.30 & 0.5934 \\
Residual & 0.13 & 12 & 0.011 & & \\
Lack of Fit & 0.13 & 10 & 0.013 & 17.22 & 0.0561 \\
Pure Error & $1.458 \mathrm{E}-003$ & 2 & $7.291 \mathrm{E}-004$ & & \\
Cor Total & 2.62 & 26 & & & \\
\hline
\end{tabular}

The regression models of cutting force $\left(\mathrm{F}_{z}\right)$, feed force $\left(\mathrm{F}_{\mathrm{y}}\right)$, thrust force $\left(\mathrm{F}_{\mathrm{x}}\right)$, and the surface roughness $\left(R_{a}\right)$ with coefficient of determination $\left(R^{2}\right)$ and adjusted $R^{2}$ equal to $95.91,98.21,96.81$, 95.22, and 91.13, 96.13, 93.09, 89.63, respectively, are given below in Eq. (6-9). 


$$
\begin{aligned}
& F_{z}=-520.511+0.773165 * V+2886.49 * f+1153.88 * d-269.327 * n p+ \\
& 0.0177083 * V * f-1.60514 * V * d+1.65346 * V * n p+1682.84 * f * d+82.6875 * \\
& f * n p-26.6896 * d * n p-0.00653913 * V^{2}-11086.8 * f^{2}-457.037 * d^{2}+ \\
& 62.1807 * n p^{2} \\
& F_{y}= 4.87759-4.32011 * V+2670.17 * f+388.194 * d-181.331 * n p-1.72594 * V * \\
& f+1.65183 * V * d+1.46147 * V * n p-167.281 * f * d+31.8 * f * n p-0.596335 * \\
& d * n p+0.0120427 * V^{2}-6902.49 * f^{2}-190.651 * d^{2}+21.2823 * n p^{2} \\
& F_{x}=2.46486-1.63901 * V+1001.03 * f+146.716 * d-68.3962 * n p-0.604167 * V * \\
& f+0.623333 * V * d+0.5515 * V * n p-63.125 * f * d+12 * f * n p-0.176543 * d * \\
& n p+0.00456523 * V^{2}-2592.99 * f^{2}-72.0949 * d^{2}+7.98364 * n p^{2} \\
& \\
& R_{a}=1.71065-0.00304714 * V-9.01806 * f+0.709725 * d+0.284886 * n p- \\
& 0.105183 * V * f-0.00831331 * V * d-0.0011108 * V * n p+0.166667 * f * d+ \\
& 1.28998 * f * n p-0.654347 * d * n p+0.0001011 * V^{2}+107.048 * f^{2}+0.281137 * \\
& d^{2}-0.100771 * n p^{2}
\end{aligned}
$$

In order to investigate the influence of nanoparticle concentration on various response variables, response surfaces are drawn in Fig 11. Fig 11(a) shows the estimated responses surface for cutting force in relation to nanoparticle concentration and feed rate, while the speed and depth of cut are kept at middle level. The lowest cutting force was recorded with a combination of highest nanoparticle concentration and lowest feed. It can be deduced from Fig 11(b) that lowest cutting force was recorded with a combination of highest nanoparticle concentration and lowest depth of cut. Figs 11(c-d) show that lowest roughness were recorded with the combination of highest nanoparticle concentration and highest speed, and highest concentration and lowest feed rate, respectively as reported by earlier researchers. 


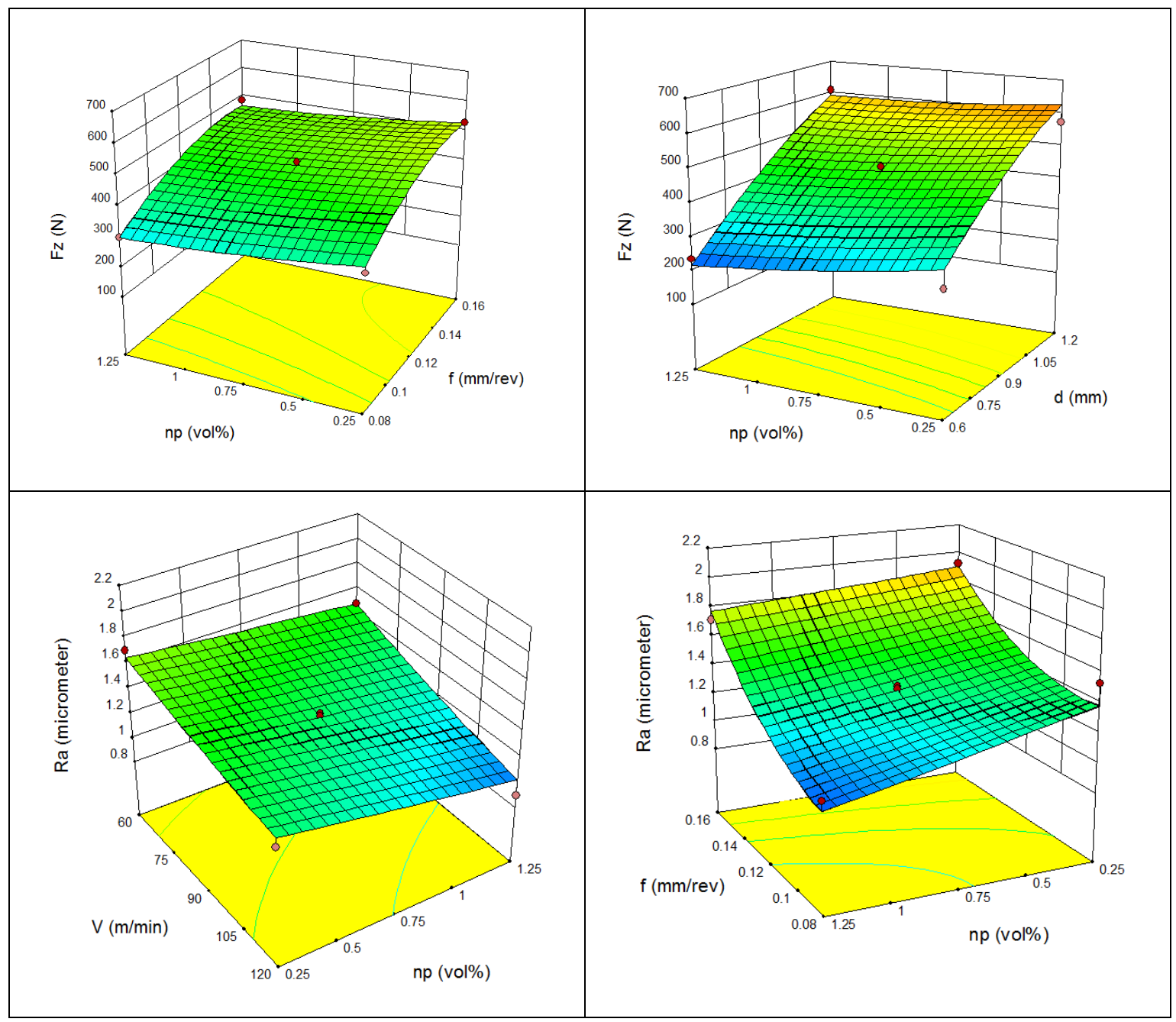

Fig 11 Estimated response surface plots for Al-GNP nanoparticle concentration (np) versus $\mathrm{v}, \mathrm{f}$ and $\mathrm{d}$

The values of response parameters $\left(F_{z}, F_{y}, F_{x}\right.$, and $\left.R_{a}\right)$ recorded during the machining using different hybrid nanofluids are tabulated in Table 11. Results clearly reveal that Al-GnP hybrid nanofluid performed better compared to monotype alumina nanofluid. Use of Al-GnP hybrid nanofluid showed a significant reduction of $9.94 \%, 17.38 \%, 7.25 \%$, and $20.28 \%$, in $\mathrm{F}_{\mathrm{z}}, \mathrm{F}_{\mathrm{y}}, \mathrm{F}_{\mathrm{x}}$, and $\mathrm{R}_{\mathrm{a}}$, respectively over alumina nanoparticle mixed nanofluid.

Table 11 Performance comparison of different nanofluids

\begin{tabular}{llllc}
\hline $\begin{array}{l}\text { Nano-cutting } \\
\text { fluid }\end{array}$ & $\begin{array}{l}\text { Cutting } \\
\text { force }\left(\mathbf{F}_{\mathbf{z}}\right)\end{array}$ & $\begin{array}{l}\text { Thrust } \\
\text { force }\left(\mathbf{F}_{\mathbf{y}}\right)\end{array}$ & $\begin{array}{l}\text { Feed force } \\
\left(\mathbf{F}_{\mathbf{x}}\right)\end{array}$ & $\begin{array}{c}\text { Roughness } \\
\left(\mathbf{R}_{\mathbf{a}}\right)\end{array}$ \\
\hline $\mathrm{Al}_{2} \mathrm{O}_{3}$ & 138.09 & 108.55 & 38.02 & 1.430 \\
\hline
\end{tabular}




\begin{tabular}{lllll}
\hline $\mathrm{Al}_{2} \mathrm{O}_{3} /$ & 124.36 & 89.68 & 35.26 & 1.140 \\
Graphene & & & \\
\hline
\end{tabular}

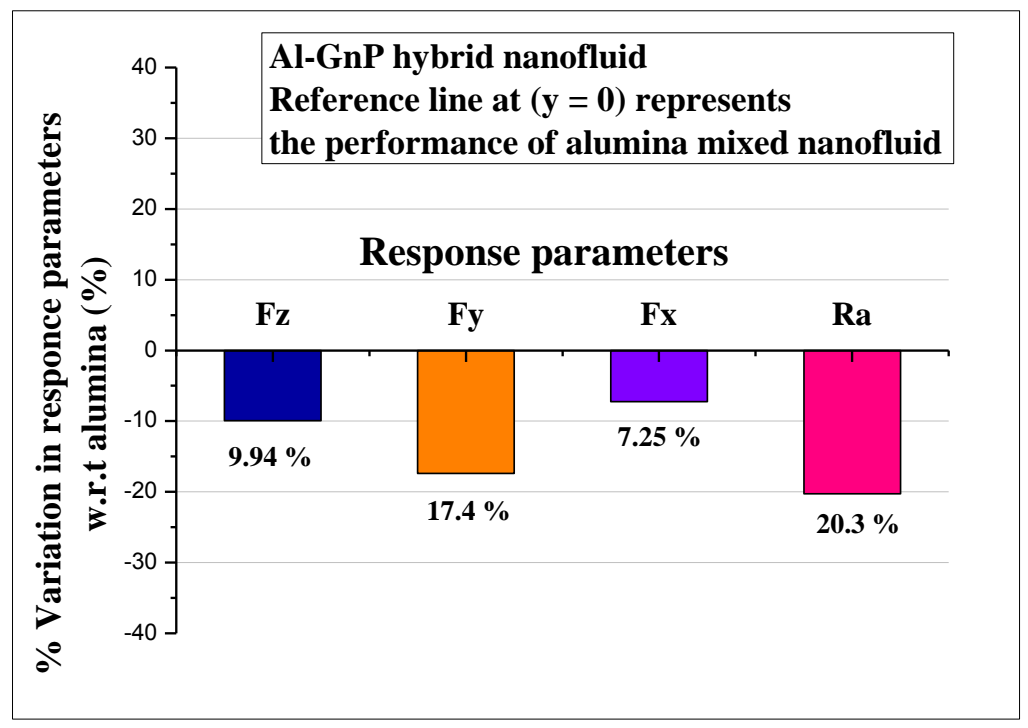

Fig 12 Effect of Al-GnP hybrid nanofluid on response parameters w.r.t. alumina nanofluid

\subsection{Cutting forces}

Table 11 shows that the lowest machining forces were recorded by using Al-GnP hybrid nanofluid. This may be because of the lowest coefficient of friction generated in the case of AlGnP hybrid nanofluid as shown in Fig 5(c) which depicts that Al-GnP possesses the lowest coefficient of friction followed by alumina nanofluid. The lower value of the coefficient of friction reduced the friction force and hence the machining forces. Additionally, the viscosity of Al-GnP hybrid nanofluid is found to be higher compared to alumina nanofluid which helped in keeping the value of friction between the sliding surfaces at lower level and hence reduced the machining forces. Moreover, the nano-layer formed between the tool and chip surface might have reduced the direct contact and could prevent the damage of cutting tool.

\subsection{Surface roughness}

Table 11 illustrates that the lowest surface roughness was achieved by the use of Al-GnP hybrid nanofluid followed by alumina nanofluid. The probable reason may be the reduced coefficient of friction and formation of liquid-film of nanocutting fluid between the sliding surfaces. Moreover, the GnP nanoparticles mixed in base fluid enhanced the nanofluids wettability as shown in Fig 8 . 
The higher wettability of hybrid nanofluid enhances the effective spreading of cutting fluid at the machining zone and between the sliding surfaces. This might be helpful in two ways; firstly it might have reduced the friction coefficient at the tool-work piece interface during the machining because of the nano-ball bearing effects of nanoparticles present in nano-film. Secondly, due to the higher contact area available over the cutting tool, the nanofluid could have extracted more heat from the cutting tool compared to alumina nanofluid with lower wettability. Therefore, the temperature rise could remain under control which helped the tool to sustain its hardness and hence the sharpness of cutting edge. A noticeable difference in the quality of surfaces could be observed in Fig 6, which clearly illustrates that good quality surface is generated in the case of Al-GnP hybrid nanofluid and hence proves it to be the superior lubricant over alumina nanofluid.

\section{Conclusions}

Present study investigates the machining performance of hybrid nanofluid regarding the machining forces $\left(\mathrm{F}_{\mathrm{z}}, \mathrm{F}_{\mathrm{y}}\right.$ and $\left.\mathrm{F}_{\mathrm{x}}\right)$ and surface roughness $\left(\mathrm{R}_{\mathrm{a}}\right) . \mathrm{Al}_{2} \mathrm{O}_{3}$ mixed nanofluid was hybridized with graphene nanoplatelets in a volumetric ratio of 90:10 to develop Al-GnP hybrid nanofluid. The optimization of different machining input variables (cutting velocity, feed rate, depth of cut and nanoparticle concentration) for response parameters using both $\mathrm{Al}_{2} \mathrm{O}_{3}$ and $\mathrm{Al}-\mathrm{GnP}$ hybrid nanofluid with RSM technique was performed. Based on the results and discussion, the following conclusions could be drawn:

- The effective thermal conductivity of all studied nanofluids increases with an increase of temperature as well as particle volume fraction.

- Al-GnP hybrid and alumina nanofluids have shown an improvement in thermal conductivity over base fluid while surprisingly; the hybridization of alumina in graphene reduced its (hybrid nanofluid) thermal conductivity. An enhancement of $9.38 \%$ in thermal conductivity was recorded for $\mathrm{Al}-\mathrm{GnP}$ hybrid, while alumina alone has shown an improvement of $9.85 \%$, over base fluid.

- The effective viscosity of all the nanofluids is found to increase with an increase in the particle volume fraction and decrease with an increase in the temperature. The Al-GnP hybrid nanofluid exhibited higher viscosity than that of $\mathrm{Al}_{2} \mathrm{O}_{3}$ mixed nanofluid.

- Hybrid nanofluids has shown a remarkable improvement in machining performances over 
$\mathrm{Al}_{2} \mathrm{O}_{3}$ mixed nanofluid. A significant reduction of $9.94 \%, 17.38 \%, 7.25 \%$, and $20.28 \%$ in $\mathrm{F}_{\mathrm{z}}$, $\mathrm{F}_{\mathrm{x}}, \mathrm{F}_{\mathrm{y}}$, and $\mathrm{R}_{\mathrm{a}}$, respectively, could be achieved by using $\mathrm{Al}-\mathrm{GnP}$ hybrid nanofluid over $\mathrm{Al}_{2} \mathrm{O}_{3}$ mixed nanofluid. Furthermore, with its use as a cutting fluid, the lowest values of $124.36 \mathrm{~N}$, $89.68 \mathrm{~N}, 35.26 \mathrm{~N}, 1.140 \mu \mathrm{m}$, respectively, could be recorded for cutting force, thrust force, feed force, and surface roughness.

\section{References}

[1] Cetin, M.H., Ozcelik, B., Kuram, E., Demirbas, E., 2011. Evaluation of vegetable based cutting fluids with extreme pressure and cutting parameters in turning of AISI 304L by Taguchi method. J. Clean. Prod. 19, 2049-2056.

[2] Hadad, M., Sadeghi, B., 2013. Minimum quantity lubrication-MQL turning of AISI4140 steel alloy. J. Clean. Prod. 54, 332-343.

[3] Sharma, A.K.; Tiwari, A.K.; Dixit, A.R. 2016. Effects of minimum quantity lubrication (MQL) in machining processes using conventional and nanofluid based cutting fluids: A comprehensive review. Journal of Cleaner Production 127, 1-18.

[4] Sarıkaya, M., Güllü, A., 2015. Multi-response optimization of minimum quantity lubrication parameters using Taguchi-based grey relational analysis in turning of difficult-to-cut alloy Haynes 25. J. Clean. Prod. 91, 347e357.

[5] Tiwari, A.K.; Ghosh, P.; Sarkar, J. Investigation of thermal conductivity and viscosity of nanofluids. Journal of Environmental Research and Development 2012, 7(2), 768-777.

[6] Yang, Y. Carbon nanofluids for lubricant application; PhD thesis: University of Kentucky, United States, 2006.

[7] Choi, S.U.S.; Zhang, Z.G.; Yu, W.; Lockwood, F.E.; Grulke, E.A. Anomalous thermal conductivity enhancement in nanotube suspensions. Applied Physics Letters 2001, 79(14), 2252-2254.

[8] Sharma, A.K.; Tiwari, A.K.; Dixit, A.R. Progress of nanofluid application in machining: a Review. Materials and Manufacturing Processes 2015a, 30(7), 813-828.

[9] Sharma, P., Sidhu, B.S., Sharma, J. 2015b. Investigation of effects of nanofluids on turning of AISI D2 steel using minimum quantity lubrication. J Clean. Prod. 108, 72-79.

[10] Lee, C.G.; Hwang, Y.J.; Choi, Y.M.; Lee, J.K.; Choi, C.; Oh, J.M. A Study on the 
Tribological Characteristics of Graphite Nano Lubricants. International Journal of Precision Engineering and Manufacturing 2009, 10(1), 85-90.

[11] Reddy, N.S.K.; Rao, P.V. Experimental investigation to study the effect of solid lubricants on cutting forces and surface quality in end milling. International Journal of Machine Tools and Manufacture 2006, 46, 189-198.

[12] Khandekar, S.; Sankar, M.R.; Agnihotri, V.; Ramkumar, J. Nano-Cutting Fluid for Enhancement of Metal Cutting Performance. Materials and Manufacturing Processes 2012, 27(9), 963-967.

[13] Park, K.H.; Ewald, B.; Kwon, P.Y. Effect of nano-enhanced lubricant in minimum quantity lubrication balling milling. Journal of Tribology 2011, 133=031803, 1-8.

[14] Alberts, M.; Kalaitzidou, K.; Melkote, S. An investigation of graphite nanoplatelets as lubricant in grinding. International Journal of Machine Tools and Manufacture 2009, 49, 966-970.

[15] Sayuti, M.; Sarhan, A.A.D.; Salem, F. Novel uses of $\mathrm{SiO}_{2}$ nano-lubrication system in hard turning process of hardened steel AISI4140 for less tool wear, surface roughness and oil consumption. Journal of Cleaner Production 2014, 67, 265-276.

[16] Amrita, M.; Srikant, R.R.; Sitaramaraju, A.V. Performance Evaluation of NanographiteBased Cutting Fluid in Machining Process. Materials and Manufacturing Processes 2014, 29, 600-605.

[17] Sarkar, J. \& Ghosh, P., 2015. A review on hybrid nanofluids: Recent research, development and applications. Renewable and Sustainable Energy Reviews, 43, pp. 164-177.

[18] X. Zhang, C. Li, Y. Zhang, D. Jia, B. Li, Y. Wang, M. Yang, Y. Hou, X. Zhang, Performances of $\mathrm{Al} 2 \mathrm{O} 3 / \mathrm{SiC}$ hybrid nanofluids in minimum-quantity lubrication grinding, Int. J. Adv. Manuf. Technol. 1-15 (2016).

[19] Ahammed, N., Asirvatham, L. G. \& Wongwises, S., 2016. Entropy generation analysis of graphene-alumina hybrid nanofluid in multiport minichannel heat exchanger coupled with thermoelectric. International Journal of Heat and Mass Transfer, 103, pp. 1084-1097.

[20] Y. Zhang, C. Li, D. Jia, D. Zhang, X. Zhang, Experimental evaluation of the lubrication performance of MoS 2/CNT nanofluid for minimal quantity lubrication in Ni-based alloy grinding, Int. J. Mach. Tools Manuf. 99 (2015) 19-33. 
[21] Abbasi, S. M., Rashidi, A., Nemati, A. \& Arzani, K., 2013. The effect of Functionalization method on the stability and the thermal conductivity of nanofluid hybrids of carbon nanotubes/gamma alumina. Ceramics International, 39, pp. 3885-3891.

[22] Kanthavel, K., Sumesh, K., \& Saravanakumar, P., 2016. Study of tribological properties on $\mathrm{Al} / \mathrm{Al}_{2} \mathrm{O}_{3} / \mathrm{MoS}_{2}$ hybrid composite processed by powder metallurgy. Alexandria Engineering Journal, 55, pp. 13-17.

[23] Young, T., 1805. An essay on the cohesion of fluids. Philosophical Transactions of the Royal Society London, 95, pp. 65-87.

[24] Wasan, D., Nikolov, A. \& Kondiparty, K., 2011. The wetting and spreading of nanofluids on solids: Role of the structural disjoining pressure. Current Opinion in Colloid \& Interface Science 16 (2011) 344-349.

[25] Montgomery, D.C., 2009. Design and Analysis of Experiments. Seventh ed. New York: John Wiley \& Sons.

[26] Gopal, A.V. \& Rao, P.V., 2003. Selection of Optimum Conditions for Maximum Material Removal Rate with Surface Finish and Damage as Constraints in SiC Grinding. International Journal of Machine Tools \& Manufacture, 43, pp. 1327-1336.

[27] Bouacha, K., Yallese, M.A., Mabrouki, T. \& Rigal, J.F., 2010. Statistical analysis of surface roughness and cutting forces using response surface methodology in hard turning of AISI 52100 bearing steel with CBN tool. International Journal of Refractory Metals and Hard Materials, 28, pp. 349-361.

[28] Dureja, J.S., Gupta, V.K. \& Dogra, M., 2009. Design optimization of cutting conditions and analysis of their effect on tool wear and surface roughness during hard turning of AISI-H11 steel with a coated mixed ceramic tool. Journal of Engineering Manufacture, 223(B), pp. 1441-1453. 